\title{
The influence of a challenge course based pre-orientation's curriculum integration on participants' perceived self-efficacy
}

\author{
Simon J. Grout \\ West Virginia University
}

Follow this and additional works at: https://researchrepository.wvu.edu/etd

\section{Recommended Citation}

Grout, Simon J., "The influence of a challenge course based pre-orientation's curriculum integration on participants' perceived self-efficacy" (2009). Graduate Theses, Dissertations, and Problem Reports. 4472. https://researchrepository.wvu.edu/etd/4472

This Thesis is protected by copyright and/or related rights. It has been brought to you by the The Research Repository @ WVU with permission from the rights-holder(s). You are free to use this Thesis in any way that is permitted by the copyright and related rights legislation that applies to your use. For other uses you must obtain permission from the rights-holder(s) directly, unless additional rights are indicated by a Creative Commons license in the record and/ or on the work itself. This Thesis has been accepted for inclusion in WVU Graduate Theses, Dissertations, and Problem Reports collection by an authorized administrator of The Research Repository @ WVU. For more information, please contact researchrepository@mail.wvu.edu. 


\title{
The Influence of a Challenge Course Based Pre-Orientation's Curriculum Integration on Participants' Perceived Self-Efficacy
}

\author{
Simon J. Grout \\ Thesis Submitted to the \\ Davis College of Agriculture, Natural Resources and Design \\ at West Virginia University \\ in partial fulfilment of the requirements \\ for the degree of \\ Master of Science \\ In \\ Recreation, Parks and Tourism Resources Management
}

Chad D. Pierskalla, Ph.D., Chair

David Smaldone, Ph.D.

Jinyang Deng, Ph.D.

Greg Corio, M.S.

Nathan Harlan, M.A.

Division of Forestry and Natural Resources

Recreation, Parks \& Tourism Resources

Morgantown, West Virginia

2009

Keywords: Challenge (Ropes) Course; Freshman Outdoor Orientation Program; College Self-Efficacy; Curriculum Integration; Adventure Education

Copyright 2009 Simon J. Grout 


\title{
Abstract \\ The Influence of a Challenge Course Based Pre-Orientation's Curriculum Integration on Participants' Perceived Self-Efficacy
}

\author{
Simon J. Grout
}

This present work employed a quasi-experimental study to examine the change of college and academic self-efficacy perception of first year students following their experience upon participation in a Challenge Course Based Orientation Program (CCBOP) covering varying levels of University 101 curriculum integration. In total 68 first year students out of an available 96 participated in the study. Four individual programs were chosen, two were randomly assigned a 'Holistically integrated' treatment $(n=37)$ and the remaining programs were assigned "Non-integrated" treatment $(n=31)$. All participants completed the College Self-Efficacy Inventory (CSEI), and College Academic Self-Efficacy Scale (CASES) prior to and immediately following the CCBOP experience.

Measurement of differences between pre-test and post-test values of both instruments by total response as well as by treatment groups was made. Non biased analysis of the CCBOP's effect upon student treatment groups was examined via determination of effect size. Mean gain score of treatment groups pre-test/post-test differences were compared via independent t-test to identify significant differences.

Results show significant increase in students' self-efficacy perception among both treatment groups on items within the CSEI and produced 'moderate' to 'large' effect sizes. 'Integrated' treatment responses generated a greater number of items of significant difference within the CASES when compared to the 'Non-integrated' treatment group. 'Integrated' treatment results show a high majority of 'large' effect sizes highlighting the treatments ability to influence participants' perceived college selfefficacy. 


\section{Dedication}

To my parents who have always been a permanent source of unconditional love and support. 


\section{Acknowledgment}

Special thanks go to all of those who have assisted me and encouraged me along the way. Thank you to everyone at the Mountaineer Adventure Program who where as eager to learn alongside me as they where to help. I would above all like to acknowledge my girlfriend whose ability to find time and strength to encourage and support me while focusing on her own education; among other things. Without your belief in my ability I would not have accomplished what I have today.

Thank You All. 


\section{Table of Contents}

Chapter Page

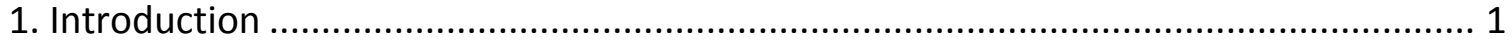

Research Questions ......................................................................................... 7

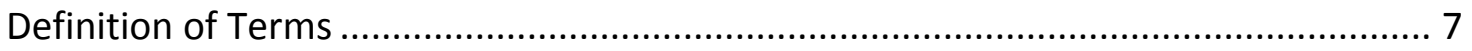

Assumptions of the Study ................................................................................... 11

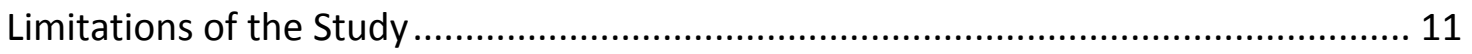

2. Literature Review .............................................................................................. 12

Adventure/Experiential Education Research and Benefits ...................................... 12

College Orientation Programs ............................................................................ 14

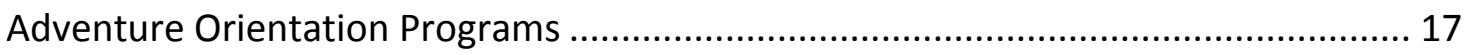

Experiential Learning ……………......................................................................... 20

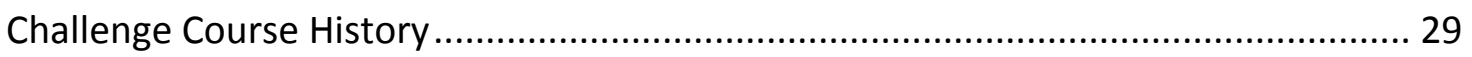

Challenge Course Research............................................................................. 30

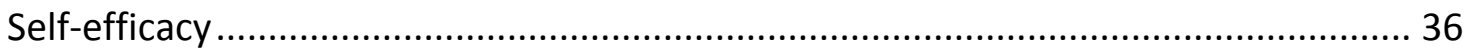

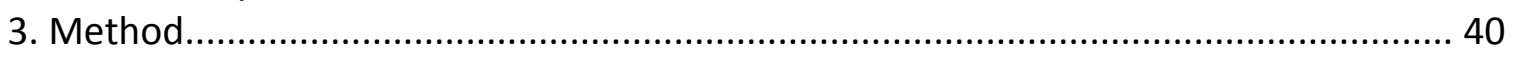

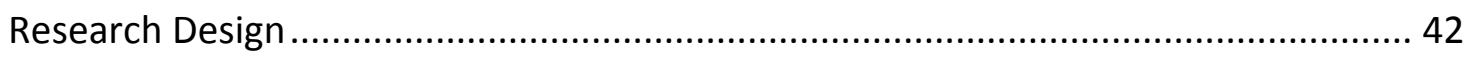

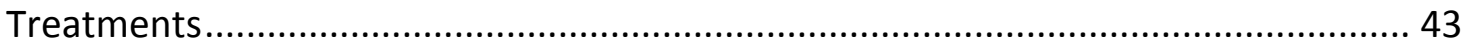

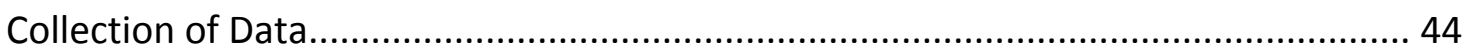

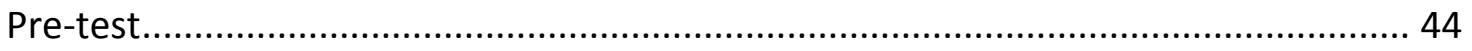

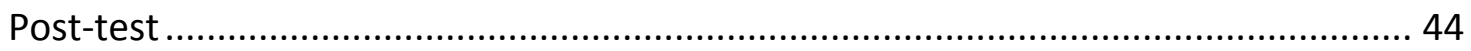

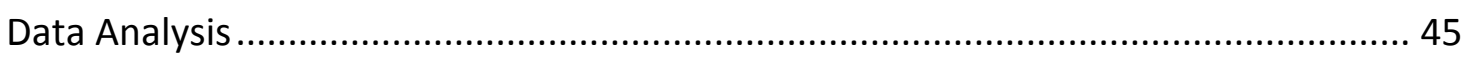

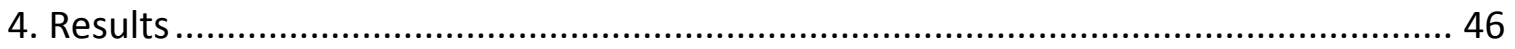

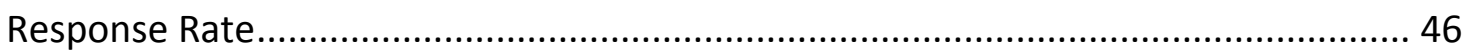

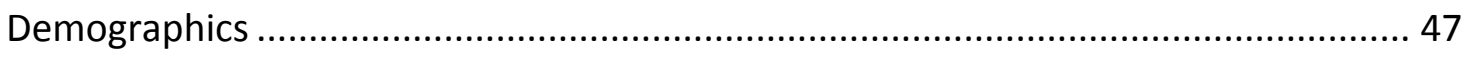

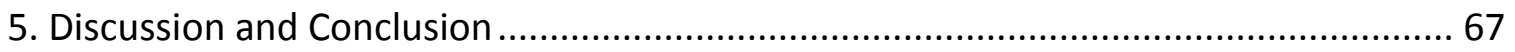

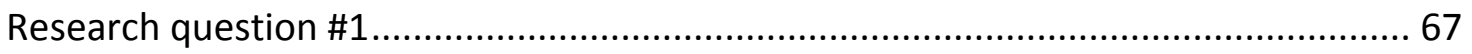

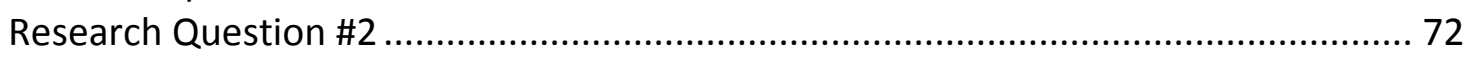

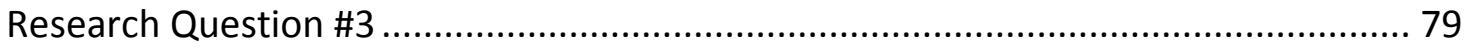

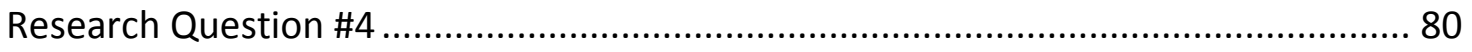

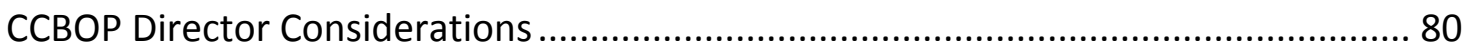

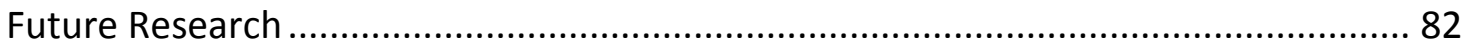

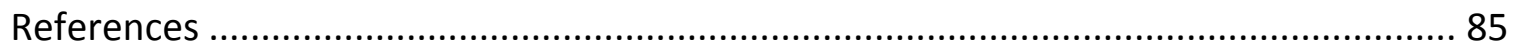

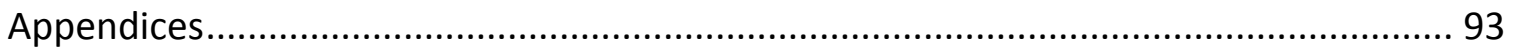




\section{List of Figures}

Figure 1: Kolb's Four Stage Experiential Learning Cycle ........................................... 25

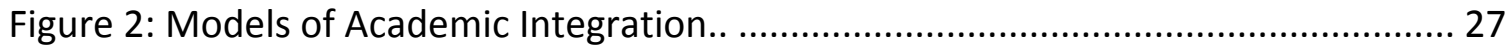

Figure 3: Four Sources of Perceived Self-efficacy.......................................................... 38

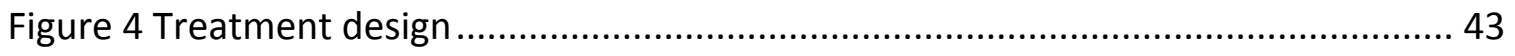

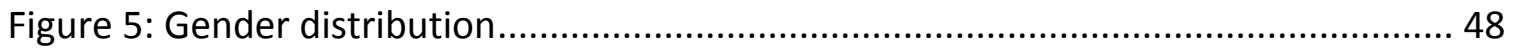

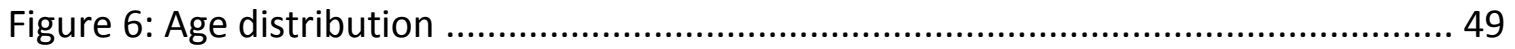

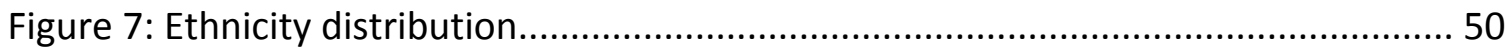

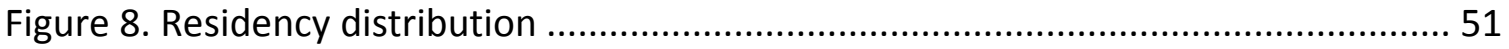




\section{List of Tables}

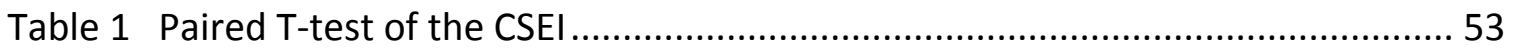

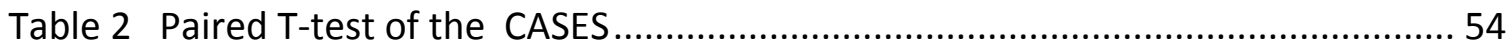

Table 3 Paired T-test of the CSEI by treatment group.............................................. 57

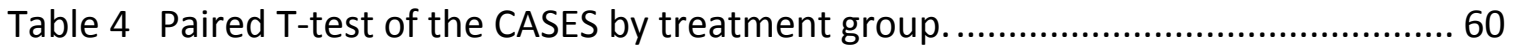

Table 5 Pre, post test and mean gain score of the CSEI by treatment group................. 63

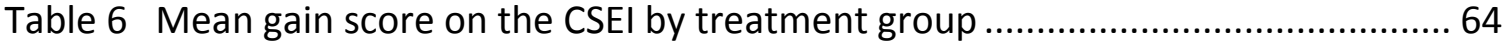

Table 7 Pre, post test and mean gain score of the CASES by treatment group ............. 65

Table 8 Mean gain score of the CASES by treatment group ....................................... 66 


\section{Introduction}

One of the most difficult periods in the life of an average American young adult is the entrance into higher education (Giddan, 1988). This transition is marked traditionally by students leaving the relative comfort of their childhood home to a complex new setting and assuming a new role. Universities are unique in the fact that students are immersed in a system that has its own values and norms in regards to not only education but social and physiological dimensions (Gass, 1986; Robison, Burns, \& Gaw, 1996). Research has shown that the first few weeks of the freshman year are crucial in determining whether students are able to make this transition. Throughout the transition and the entire secondary education experience there are many different and unique challenges to be navigated. The higher one's belief in being able to meet these constraints the more likely one is to negotiate, persist and be successful (Bandura, 1994). Being academically prepared is one such challenge which has received years of attention within higher education institutions; however, the need to feel comfortable and accepted into the new environment also plays a large role in perseverance and success. By being socially accepted into the university culture, feeling comfortable in their new environment and by being successful, students are more likely to persevere (Robison et al., 1996).

Universities and colleges have recognized this need to assimilate new students into their new environment. Institutional use of first year seminars such as University 101 is one such approach which has been shown to provide beneficial results. As cited in Porter and Swing (2006), research into first year seminars has shown that students who participated on average 
have higher grades during their first year, are less likely to be on academic probation, are more involved on campus, and report greater interaction with faculty. A tribute to these research findings is the extent to which higher education institutes utilize this type of program, nearly $84.8 \%$ of all institutions ("History of the first year seminar," n.d.).

Although differences exist between various program lengths, timing and quality, nearly all of them focus on outlining the expectations of the institutional administration and integration of students into the institution's culture (Bell, 2006). By adequately presenting the institutions expectations, students are able to assess the level to which they feel they can meet those expectations. This has been accomplished in a variety of ways. In order to effectively communicate to different learning styles the use of small group discussions, skits and songs, interactive presentations, lectures and speeches have been used (Fox, Zakley, Morris \& Jundt, 1993).

Several different approaches have been used to assist students in this transition; one which has gained in popularity over the years is the use of wilderness orientation programs. Originating from Dartmouth's Outing Club wanting to take student hiking prior to the beginning of classes in 1935 (Dartmouth Outing Club, n.d.), these programs have expanded to more than 200 universities (Bell, 2008). These current programs range in the activities utilized (e.g., backpacking, canoeing, climbing, ropes course); the number of participants ( 4 to 1,080 people); the length of program (1-24 days); and the cost (\$0 to $\$ 212$ per day) (Bell, 2008).

Gass (1986) examined the relationship of wilderness orientation programs and college student's attrition rates. GPA, actual retention rates and a shortened Student Developmental Task Inventory (SDTI) scores significantly differed between the experimental and control 
groups. After the second semester students exposed to the treatment demonstrated better performance in all areas examined (Gass, 1986). Unfortunately, questions exist as to the external validity of the study and within the research design. Despite the inability to generalize the results due to design flaws, this study still adds insight into anticipated program outcomes.

More recent research focused on the social support benefits of a wilderness preorientation program compared to a variety of other pre-orientation programs. The development of the Campus-Focused Social Provisions Scale proved to be successful and was used to examine students change in support network (Bell, 2006). Significant differences between the wilderness pre-orientation program and all other programs were reported (Bell, 2006).

Wilderness orientation programs can be made up of a variety of activities. One such program which developed from experience based adventure education that has made a transfer into the traditional educational system is the use of challenge courses. These experiential educational tools have been utilized in therapeutic settings, corporate training, group development and middle and high schools (Rohnke, Rogers, Tait, \& Wall, 2007). Utilizing components such as games and initiatives, low elements as well as high elements, practitioners have focused on outcomes such as increased self-esteem, greater sense of trust and teamwork, self-efficacy, locus of control, enhanced communication and group cohesion (e.g. Hatch \& McCarthy, 2005; Stadler \& Kotze, 2006; Wolfe \& Samdahl, 2005).

For every study which discovers a connection between challenge course participation and desired benefits, there is a question as to whether they are long persisting (Wolfe \& Samdahl, 2005). However, one such outcome that has received widespread credibility is self-efficacy. 
Gillis and Speelman's (2008) meta-analysis of the field of research on challenge courses uncovered a 'medium' effect size for the outcome of self-efficacy which has practical implications. When compared to self-esteem, which had nearly three times as many studies conducted, self-efficacy's effect size was nearly double (Gillis \& Speelman, 2008). Self-efficacy is defined as "one's belief about their capabilities to produce designated levels of performance that exercise influence over events that affect their lives" (Bandura, 1994, p.72). Self-esteem on the other hand "is an expression of an attitude of approval or disapproval and indicated the extent to which a person believes himself/herself capable, significant, successful, and worthy" (Coopersmith, 1990, p. 5). Evaluation of one's self-efficacy can be a component of examining ones self-esteem. Gillis and Speelman (2008) go on to suggest that self-esteem, even though it is the most widespread construct examined, is not as prevalent or powerful of an outcome as self-efficacy. With this evidence suggestions have been made to further explore this benefit and how it is brought about.

Self-efficacy stated another way, is seen as one's appraisal of their capability with regards to how well they feel they could perform a course of action necessary to handle a prospective situation (Bandura, 1982). Self-efficacy beliefs determine how people "feel, think, motivate themselves and behave." (Bandura, 1994, p.72) This personal belief has been a reliable predictor of perseverance, success and accomplishment regarding pain tolerance, career development, academics and adventure activities (Hackett \& Betz, 1981; Litt, 1988; Propst \& Koesler, 1998; Sanders \& Sanders, 1998). Self-efficacy is seen as a vital part of a successfully transition into new and demanding environments. The level to which students feel they are 
capable of accomplishing specific tasks required for a successful transition, the more likely they are to successfully transition into the college life.

As previously mentioned the use of wilderness pre-orientations, more specifically challenge course based pre-orientation programs (CCBOP), have become prevalent in combating the complexities of transitioning from high school to the living and learning environment of college (Giddan, 1988). With its ability to elicit general self-efficacy, a challenge course program for students preparing for college life would be a logical connection in promoting student success. West Virginia University has placed emphasis on this connection with the construction of a new challenge course facility in the summer of 2007 to be utilized by their freshman outdoor orientation program, Adventure West Virginia.

Through examination of the literature there is a desire to move beyond simply showing a connection between an adventure education program and its associated benefits. Ewert's (1987) analysis of trends in outdoor adventure produced a viable next step in research. He recommended further investigation as to which characteristics of a programmed experience expressly influence the outcomes observed. A shift in the research is needed, from asking what the outcomes are, to what aspect of the experience generated the desirable outcome? This can be accomplished through systematic quantitative investigations of programs (Ewert, 1987). Investigating challenge course program design characteristics that influence outcomes would help practitioners and managers know if they are meeting the goals of the participants. One such characteristic which has received attention with nearly all challenge course programs is the type of facilitation conducted. Facilitation learning through a direct experience is a balance of science and art. However, the aspects of facilitation framing, frontloading, briefing 
and debriefing that produce the most potent of outcomes is not understood. When it comes to effective use of an educational curriculum, the idea of integrating curriculum into experiences, or curriculum based on experiences, seems difficult to conduct.

Models of Integration (MOI) C , 1999, developed by the Christian Campus Outreach (CCO), is one model that incorporates faith-based components. The four models that are typically adhered to are 'Non-integrated', 'Pseudo integrated', 'Partial integrated', and 'Holistically integrated' (Harlan \& Grout, 2008). These individual models are associated with a certain level of connection between the specific curriculum and the challenge activity. 'Nonintegrated' is seen as a complete disconnection between activity and curriculum. The activity is seen as only a platform from which a typical lecture on the curriculum is then given with minimal connection drawn from the experience. 'Holistically integrated' on the other hand involves the incorporation of curriculum throughout the experience and the experiential learning process. The curriculum is presented as part of the activity, has a direct connection to the activity and is able to be lived out throughout the activity to the point where the participants have embodied the information and learning.

Facilitators and practitioners have used this approach of facilitation to varying degrees. A question is therefore posed that if 'Holistically integrated' curriculum is deliberately emphasized, will participants have a greater perception of anticipated outcomes and will this enhance their overall learning? This is the problem to be investigated throughout the following pages. 
The purpose of this study is to:

(1) examine the connection between challenge course based orientation programs and students perceived college and academic self-efficacy;

(2) examine the effects of 'Holistically integrated' and 'Non-integrated' curriculum approaches on student's perceived college and academic self-efficacy; and

(3) identify if any socio-demographic factors are related to college and academic self-efficacy.

\section{Research Questions}

1. Does a university's challenge course based pre-orientation programs elicit changes in participants' perceived academic self-efficacy and/or perceived college self-efficacy?

2. Does a higher level of curriculum integration of the challenge course based preorientation program elicit any change in participants' perceived academic self-efficacy and/or college self-efficacy?

3. What is the socio-demographic makeup of the sample of participants?

4. What socio-demographics differences, if any, have influence on participants' perceived academic self-efficacy and college self-efficacy?

\section{Definition of Terms}

\section{Self Efficacy:}

“Perceived self-efficacy is defined as people's beliefs about their capabilities to produce designated levels of performance that exercise influence over events that affect their lives. Self- 
efficacy beliefs determine how people feel, think, motivate themselves and behave." (Bandura, 1994, p.72)

Through the development of the concept of self-efficacy, Bandura identified four major sources that influence one's perceived self-efficacy. Mastery experience, considered the most influential of sources, is based on the concept of a previous successful experience increasing one's self-efficacy belief, whereas failure tends to diminish it. However, the level of challenge present in each subsequent success and failure plays into the vicarious experiences, social persuasions, reduction in stress reactions and altered negative emotional predispositions, and is an interpretation of the physical state of the individual (Bandura, 1994).

\section{First-year Students:}

A first year student is a student who is enrolled in their first year of courses at any given university or college.

\section{Experiential Education (Adventure Education, Experiential Learning, Outdoor Adventure}

\section{Education, Challenge Education, and Wilderness Experiential Education):}

The Association for Experiential Education offers a concise definition for experiential education which is:

"Experiential education is a philosophy and methodology in which educators purposefully engage with learners in direct experience and focused reflection in order to increase knowledge, develop skills and clarify values." (Association of Experiential Education [AEE], 2007).

This is a rather broad overview; however, the Association for Experiential Education goes on to further outline key principles that define and unify all forms of experiential education. Of these the ability to elicit learning via specifically sequenced experiences which 
are carried further by reflection, critical analysis and synthesis (AEE, 2007) has the greatest relevance to this study.

Experiential Education can occur in a variety of settings, focused on a variety of outcomes. The most common settings are remote wilderness, national, state or city public lands, public and private schools and indoors locations such as conferences centers and nonprofit or for profit establishments. Typical activities include, camping, backpacking, rock climbing, mountaineering, general exploration, challenge courses, games, initiatives, and group challenges or tasks. These types of program outcomes can focus on but are not limited to recreation benefits, team development, corporate training, environmental education, therapeutic counseling, self exploration and personal development (AEE, 2007).

\section{Challenge (Ropes) Course:}

Challenge courses typically consist of a series of unique problem solving activities constructed of poles, cables, platforms, trees, ropes and various other materials that vary from ground level to $40-50 \mathrm{ft}$ above the ground and utilizing belay systems. All tend to necessitate physical, mental, emotional and interpersonal qualities to successfully negotiate the problems presented. Activities can involve individuals, pairs or entire groups depending on the desired outcomes of the program. Typical focuses of these programs can be "a broad range of activities, including education, recreation, therapy, and organizational development" (Neil, 2006, para. 6). Typical participants of challenge courses range from students to professionals who participate in programs lasting from only a few hours to an extended series of days (Neil, 2006). 


\section{University 101:}

A standardized new student seminar college orientation curriculum originating from South Carolina University in 1972 had goals such as increasing retention, developing more positive attitudes toward university and improving a student's understanding of the purpose of higher education. ("History of the first year seminar," n.d.).

\section{Adventure Pre-Orientation Programs:}

An adventure orientation program is considered a pre-orientation program which utilizes adventure/challenge activities as a tool to assist in helping students adjust and integrate into the college community. These are usually small group groups of 8-12 first year students led by trained upperclassmen taking place in wilderness and/or wilderness-like areas during the summer prior to the start of the first semester (Bell, 2006).

\section{Curriculum Integration:}

For this study curriculum integration will be defined as the level at which traditional educational curriculum (University 101 orientation curriculum) is interwoven with challenge course activities. To further distinguish it 'Non-integration' is the lack of connection between activities and the curriculum, which is usually associated with a distinct break between the activity and presentation of the curriculum, with minimal reference to one or the other. A 'Holistically integrated' curriculum can be identified as a deliberate attempt to incorporate the curriculum into the activity. Attempts to make multiple and direct connections to curriculum through the common experience of the challenge course activity are made by frontloading, framing, briefing and debriefing activities and the use of metaphors. Metaphors are used as bridges connecting the activities and curriculum to the individual's broader world. The 
curriculum is presented at an opportune time within the activity and is given to the participants as a new resource that can aid in the completion of the activity.

\section{Assumptions of the Study}

For the proper interpretation of data, results, conclusions and implications several assumptions about the study must be recognized.

- All facilitators were consistent in their presentation of each program excluding the variables of curriculum integration which is being examined.

- All study participants evaluated and answered each survey item honestly.

\section{Limitations of the Study}

For the correct interpretation of data, results, conclusions and implications, several limitations of the study must be recognized.

- Due to small sample size, program attributes unique to Adventure West Virginia's CCBOP's design and the focus on College and Academic Self-Efficacy, findings can be generalized only to programs of high similarity.

- A self-selection bias may have occurred, affecting the results. Students were not randomly selected to participate in Adventure West Virginia's CCBOP; however, individual trips within Adventure West Virginia's CCBOP were randomly assigned one of two treatments.

- Due to the multi-dimensional nature of conducting a study in a multiple day, outdoors based program, several variables that are unable to be controlled by the study may have influence on the variables being examined by the study. 


\section{Literature Review}

\section{Adventure/Experiential Education Research and Benefits}

The recognition that Outward Bound School programs and similar program experiences have unique effects on many facets of participants' lives can be seen due to the expansion of such programs (Hattie, Marsh, Neil and Richards, 1997). Prior to the 1950 s many instructors, program directors and even participants noticed changes after participation in certain activities but could not decisively say what had happened. In order to justify the attention being focused on this movement researchers have set out to empirically identify and document the outcomes or effects of adventure-based experiential learning activities. Beginning in the 1960s and through the 1970s there was an increased focus on understanding the social and personal benefits of participation in wilderness adventure activities (Ewert, 1987).

Several early pieces of research provided "relatively conclusive evidence that adventurebased activities can produce socially desirable benefits" (Ewert, 1987, p. 16) (e.g. Kelly and Baer, 1968; 1969; 1871; Moses and Peterson, 1970). In the later years of the movement and even up to the present day most emphasis has been placed on individual benefits and the most extensively examined topic of self concept (Ewert, 1987; Hattie et al., 1997). The last area of general research in the late 1970s, which has continued to the present day, has been termed 'wilderness experience' and focuses on why participants take part and what their expectations are (Ewert, 1987).

As shown, many different approaches have been taken in order to determine the expected outcomes of educational process within adventure experiences (Wolfe \& Samdahl, 
2005). Links have been made connecting these programs to positive effects on participants (e.g. Dougherty, 2005; Goldenberg, Klenosky, O'Leary, and Templin, 2000; Priest and Lesperance, 1994).

Burton's (1981) findings reiterate the inconsistencies within the research available. After analysis of 161 independent studies his findings on the programs' positive effects is as varied as the approaches used. Close to the same percentage of studies found programs to have 'mostly significant' effects as those having 'non-significant' effects. Providing evidence that not all adventure experiences are inherently positive (Hans, 2000; Neil and Richards, 1998).

Through their meta-analysis of previous research, Hattie et al. (1997) outlined 40 major adventure program outcomes researched up until 1996. These outcomes included 6 main categories: leadership, self concept, personality, interpersonal, and adventuresome, with self concept having the highest number of sub domains as well as the largest effect size. Through their analysis Hattie et al. (1997) indicated that the majority of support for the research concept that adventure programming can enhance participant's self concept. Similar findings are also reported by Neil and Richard's 1988 study; however, other research indicated that programs are ineffective at eliciting any change (e.g. Gillis, 1981; Powers, 1983; Stoger, 1978). Ewert (1987) indicated that the evidence for beneficial outcomes is too large to ignore and question.

Self concept sub domains that have seen the greatest increase in research activity include independence, confidence, self-efficacy and self understanding. Some self concept studies have concluded that the focus should be on each sub-domain in order to lend credibility and a clearer description of individual factors contributing to self concept as opposed to examining self concept as a whole (Hans, 2000). 
Some major concerns raised about adventure education research were pre-group anxiety and post-group euphoria and the difference of outcomes dependent on background, age and gender. After deeper investigation, pre-group anxiety did not have a significant effect and is therefore of no real concern (Hattie et al., 1997) Post-group euphoria on the other hand has been seen to effect participants responses. Neil and Richards (1998) feel that this euphoria may lead to inflated emotionally charged responses with the overall group dynamic masking the individual's analysis. The use of a follow up test will more accurately indicate any increase from pre to post test by showing that the effect level has remained at that post activity level, returned to pre activity level, or if it in fact has continued to increase.

Several researchers have agreed that an overwhelming number of studies have been conducted to support the overall efficacy of adventure programming and associated outcomes (Burton, 1981, Ewert, 1987, Gillis \& Speelman, 2008, Hans, 2000, Witman, 1993). However, there is still concern as to what specific characteristic produce these outcomes. Several studies attempted to discover and define what characteristics create or at least have a substantial effect on program outcomes (e.g. Dougherty, 2005; Yoshino, 2004). Unfortunately, these studies were too small to generalize, too flawed to be considered valid or were unable to truly make any viable connection. However, incremental and quantifiable data which makes an attempt to build upon the pre-existing research is beneficial to the field (Ewert, 1987; Hans, 2005).

\section{College Orientation Programs}

Transitioning from a comfortable and predictable routine of high school and home to the multidimensional complexities of the living and learning environment of college has been 
considered the most challenging period of an adolescent's life (Giddan 1988). Learning where one fits into the university community, which has been identified as a unique microcosm of society emphasizing its own values, personal, social and educational norms, is important for a student's smooth transition (Gass, 1986; Robinson, Burns \& Gaw, 1996). Higher education institutions provide assistance with this experience through college orientation programs and/or classes.

Boston College has been credited with developing and implementing the first of these programs in 1888, and the first institution offering college credit was in 1911 at Reed College (Gordon, 1989). Over the years there has been an ebb and flow of orientation programs and courses but from decade to decade an overall marked increase is apparent (Gordon, 1989). Even with continual re-design and different formats, structure and timing the history of orientation programs show three general areas of focus on transition and adjustment: physical, social and academic (Tinto, 1987; Robinson et al., 1996).

Seen as a three phase process, orientation starts with the student's initial contact with the university or pre-admissions, continues with pre-enrollment through early enrollment and ends with the commencement of the first year (Perigo \& Upcraft, 1989). The exact boundary where each phase begins and ends is unclear. Each individual student initiates these phases at different times; however, the institutions mark the deadline and dictate proper information, experiences and activities needed for a smooth transition throughout that phase (Pergo \& Upcraft 1989). For the purpose of this study an orientation period will be considered from early enrollment to the beginning of fall classes. 
In Robinson et al.'s (1996) survey of 273 colleges and their orientation programs, it was shown that academically focused programs lent insight to incoming first year students on requirements and procedural necessities. Placement testing, academic advising, course registration, tuition payments, financial aid requirements are all in the forefront of these types of program which generally take place at pre-admission to pre-enrollment. The social and physical orientation within the university and its culture take place much closer to the beginning of classes rather than during the summer prior to registration. Focus is spent on community building between peers, upperclassmen, faculty and staff. This is also the period where information is given on subjects including personal health and safety, student support services, student organizations, and college survival skills.

The last portion of orientation commonly takes place throughout the first semester. This usually manifests itself in the more traditional University 101 course made popular by the University of South Carolina (Gordon, 1989). These are classroom courses loaded with a wide range of topics but mainly focus on academic integration tips and skills, personal health and safety and time management skills, but lack an emphasis on community building or social integration. The majority of courses are offered for credit and many institutions, especially smaller ones, require all freshmen to enroll (Robinson et al., 1996).

Specific characteristic of orientation programs to consider, the first year students peers and academic advisors, can both be a key source of information being shared during the transitional period. These two sources of information are unique in what they offer to the process. Fellow students are able to offer personal experiences and to speak honestly and directly about important issues and the norms of the university or college. This peer interaction 
offers insight on higher education and the transition into university life that cannot be captured in any other manner (Fox et. al., 1993, Gordon, 1989). On the other hand, academic advisors are able to initiate the relationship focused on identifying and arranging resources necessary for success early on in new student careers. It must be stressed that multiple and varied ways of conveying the required information is necessary to meet the many different learning styles of students and to reinforce learning (Fox, et. al., 1993). To provide this variety many campuses use small group discussions, plays and skits, interactive presentations and lectures or speeches (Fox, et. al. 1993).

Many institutions have seen a benefit to incorporating all aspects of the orientation process into one large multi-faceted program. These programs focus on academic, social and physical integration which are brought about by a wide range of activities, events and programs; however, when and how these programs occur and where the emphasis of adjustment is place depends upon the institution. Wilderness adventure activities are one such program which uses the common experience of participating in novel outdoor activities as a platform for communicating the institutions' desired orientation information.

\section{Adventure Orientation Programs}

Adventure orientation programs provide an innovative way in which higher education institutions approach the three main integration topics necessary for a smooth transition into college life (Davis-Berman and Berman, 1996). A wide range of program structures can fall under the broad title of adventure orientation program; each is based upon how individual institutions perceive adventure programs. These structured programs include but are not limited to challenge courses, backcountry excursions, other outdoor activities or overnight stays 
in remote cabins or lodges. The choice of activity is dependent upon the goals and objectives of the institution, availability of universities' financial and time resources as well as the general feasibility of the program (Fears and Denke, 2001).

Even though several orientation programs of this type have been well established since the 1960s, few professional articles have been published (Gass, 1990; Davis-Berman and Berman, 1996). This has been recognized recently; however, the response has been mainly studies in the form of unpublished theses and dissertations. Several professionals of academia have been able to establish themselves in the area of adventure orientation program research and literature (Davis-Berman \& Berman, 1996).

Gass (1983) adapted the Outward Bound model to establish a program at University of New Hampshire, and conducted several studies. Over 12 and 42 month periods students exposed to the treatment of the adventure pre-orientation program experienced significantly higher retention rates. Years later Gass, Garvey and Sugerman (2003) examined the long term effects of the same programs. They were able to show that 17 years after their participation, graduates still associate much of their college direction and success to the experience gained during summer adventure orientation programs (Gass et al., 2003).

In light of the increase in adventure orientation programs being offered at universities, Galloway (2000) examined commonalities in activities, missions, goals and objectives. Findings indicated that the objectives for the majority of programs simply focused on generic outcomes associated with general adventure programming as opposed to anything university related. These included promoting positive peer group development, enhancing self confidence/self esteem, having fun and personal adjustment/maturity. Generating a specific focus on college 
preparation a number of programs influence indicated an improvement in decision-making skills, setting student expectations, preparation for college academics and the reduction stereotyping. The study activities employed to meet these goals included group processing, fireside discussions and camp cooking. These are smaller but necessary components of the heavily emphasised daily activities of rock climbing, backpacking, canoeing, community service or low/high challenge courses.

With the wide range of goals and activities frequently utilized, researchers have begun an attempt at linking program features to specific outcomes. After looking into the relationship between college pre-orientation programs and social support, Bell (2006) found that wilderness orientation programs showed significant social support development across all of the CampusFocused Social Provision Scale's sub levels of attachment, guidance, tangible support, social integration, competence and nurturance. Even though they are programmatically similar (community service orientation programs), participants made no marked social support development compared to those not involved in any orientation program. Other studies have; however, shown that participation in generic community service (Astin, Vogelgesang, Ikeda and Yee, 2000) can have a positive direct and indirect effect on a student's interpersonal skills, selfefficacy, and leadership activities.

A preliminary study examining general self-efficacy gains of adventure orientation participants and the ability for it to transfer to task specific self-efficacy measures was conducted in recent years (Jones and Hinton, 2006). Initial data has shown that results of the Perceived Competence of Functioning Inventory (PCFI) increased between post-test and 8 week follow-up interval, with the 8 week follow-up producing the only statistically significant 
difference (Jones and Hinton, 2006). A connection between specific and general self-efficacy was not possible due to low response rates preventing a full analysis of the data (Jones and Hinton, 2006).

\section{Experiential Learning}

Human learning is a complex and complicated process which leads to understanding, knowledge, and if truly effective, provides a solid preparation for future situations that may occur. The major focus of adventure based experiential learning is this notion of preparation which is derived from the concept of transferable learning (Gass, 1985). Although the idea of adventure based experiential learning is relatively modern compared to other educational approaches, experiential learning has its roots in the teachings of philosophers like Plato, Socrates and more recently Kant and Dewey (Crosby, 1981).

Perhaps the most recognized and out spoken proponent for learning through individual experience is the American philosopher John Dewey. Through his pragmatist philosophical view he commented on subjects such as education, ethics, religion, social philosophy and logic from the late 1880s until his death in 1952 (Stuhr, 1987). Writing on a variety of issues throughout his career, Dewey's ultimate focus and passion was for development of the ideals of a democratic society through education. His words have been championed in the development of many outdoor adventure programs and the directions that they have taken. Perhaps the most relevant writing is "Experience and Education" in which Dewey explains how individual experience can lead to greater understanding and education when properly harnessed and facilitated. 
Dewey states that along with the thought that all genuine education is derived from experience, not all experiences are necessarily educative (Dewey, 1938). Experience can even be considered mis-educative if it "has the effect of arresting or distorting the growth of further experience" (Dewey, 1938, p 25-26). This may result in a "lack of sensitivity and of responsiveness" limiting the possibility of gaining richer experiences in the future (Dewey, 1938, p 25-26). An improperly presented or directed experience can dissipate energy with it, producing disconnectedness with all other experiences. This ultimately lends itself to the production of habits having an "inability to control future experiences" (Dewey, 1938, p 26).

This complexity in experience and learning produces interdependence between the learner and the environment. In addition to be truly educative a situation must have a high level of continuity to previous situations as well as an anticipated connection to future events (Dewey, 1938). A utilization of one's surroundings, both social and physical, that are available and relevant allows for the highest level of educative content from an experience (Dewey, 1938).

Promoted by Dewey, this concept of learning through relevant and highly correlated experiences has been taken by adventure based programs such as Outward Bound to set the process framework for powerful and effective programming. Outward Bound's adoption and embodiment of the philosophy of experiential learning allowed it to become the modern experiential adventure education industry known as the Outward Bound Process (Walsh and Golins, 1976). This modern Outward Bound Process and the early philosophy of Dewey tend to be considered by the majority of practitioners as one in the same. 
Walsh and Golins (1976) defined and outlined this process in their work entitled "Exploration of the Outward Bound Process". It is important to recognize that a process is merely "a generalized series of conditions, events and objects which interact to produce a desired effect" (Walsh and Golins, 1976, p. 1). With any educational, and additionally, any outdoor educational process there are many different conditions and events to consider. Beyond the learner, the instructor, and the physical and social environment, probably the most recognizable component specific to the Outward Bound Process is the utilization of "characteristic problem-solving tasks" (Walsh and Golins, 1976, p. 6). These tasks are organized with the assumption that they are planned, programmed and managed for the anticipated outcome. They are incremental in their complexity and level of difficulty. Concrete and distinctively recognizable as a problem with a clear time frame they are additionally manageable, consequential and most importantly holistic, in the sense that they necessitate the utilization of an individual's physical, mental, emotional and social resources to be successful (Walsh and Golins, 1976).

The combination of the physical and social environment enable the learner and instructor together with the 'characteristic problem-solving task' (Walsh and Golins, 1976, p. 6) to create an environment of dissonance or discomfort that can be resolved through mastery of the task. Through this resolution much of the personal learning is present, yet it tends to be overlooked, hidden and disguised. This type of personal learning is only displaying itself as a vague awareness that is difficult to understand (Dewey, 1938). The role of the instructor is to guide this experience so it does not remain hidden or become a source of wasted energy or even a "mis-educative" experience (Dewey, 1938). The specific roles of the instructor are 
many; however, most importantly they must be an effective facilitator guiding the learner through the creation of a bridge from the experience to their personal life. In addition, the instructor should provide an opportunity for the learner to reflect on the use of mastery skills that aid in the success of characteristic problem-solving tasks which mirror other current and anticipated future situations in the learner's life (Walsh and Golins, 1976).

This transfer of learning is considered the source of highest learning and can be enhanced by the instructor or facilitator through the use of individual and group reflection and debriefing (Bacon, 1983). Most commonly isomorphic metaphors, those based upon situations with paralleling structure, are used in aiding and directing the transfer of learning (Bacon, 1983). This transfer of learning is present in all education in one fashion or another; however, it is also a key characteristic of experiential education (Gass, 1985). The deliberate use of metaphors and desire to produce specific transfer is the task of experiential educators. McGowan (1997) outlines further the role of educators' ability to influence learning and how metaphors are utilized.

Instructors must carefully choose and actively interpret course activities as metaphors to further educational and therapeutic goals that lie outside the present experience. Archetypal endeavors and relationships are to be programmed as patterns of behavior to help participants to change their present behaviors so that they more closely resemble those encapsulated in the metaphor. This is accomplished subconsciously through the design of the course activities and consciously by verbally comparing and contrasting participant patterns of behavior with the ideal archetypal pattern through processing the experience (McGowan, 1997, p.15)

The deliberate design and use of techniques outlined and used in the Outward Bound

Process has infiltrated the adventure education industry, but has given even further structure to the controlled and developed field of challenge course facilitation. Both of these are 
commonly rooted in the Outward Bound Process through Kolb's Experiential Learning Theory and the experiential learning cycle.

David Kolb's experiential learning model (1984) defines learning as "the process whereby knowledge is created through the transformation of experience. Knowledge results from the combination of grasping and transforming experience" (p. 41). It consists of two distinctive modes of understanding one's experience and two additional modes of transforming that experience into new learning and understanding. This model is cyclical and therefore able to begin and terminate at various points however, the learning generally commences with a concrete experience (Kolb, Boyatzis and Mainemelis, 2000). This is typically described as the active participation of the learner within a situation resulting in real, vivid and concrete outcomes and repercussions. However, simple passive observation of others in various situations can provide the same information. Both of these experiences form the basis for observation and reflection, the second way in which the experience can be grasped. From this point the observations are sorted, organized and distilled in order to produce 'abstract generalizations' that are based upon the reflection of the experience and its observations. This intake of observations and the synthesis of theories or inferences of action and reaction is the new framework from which new experiences are viewed and understood (Kolb et al., 2000).

As mentioned, due to the cyclical nature of the model experiential learning can commence during any of the four stages; however, it must progress and appropriately build from the entry point. Regardless of which stage the process starts at, the most important aspect is ensuring solid connections are made between all stages (Healey and Jenkins, 2000). The most ideal and actually most likely process involves one cycle leading into another 
revolution through the stages; the cycle therefore should be seen as a series of spirals built upon one another rather than a single rotation (Healey and Jenkins, 2000).

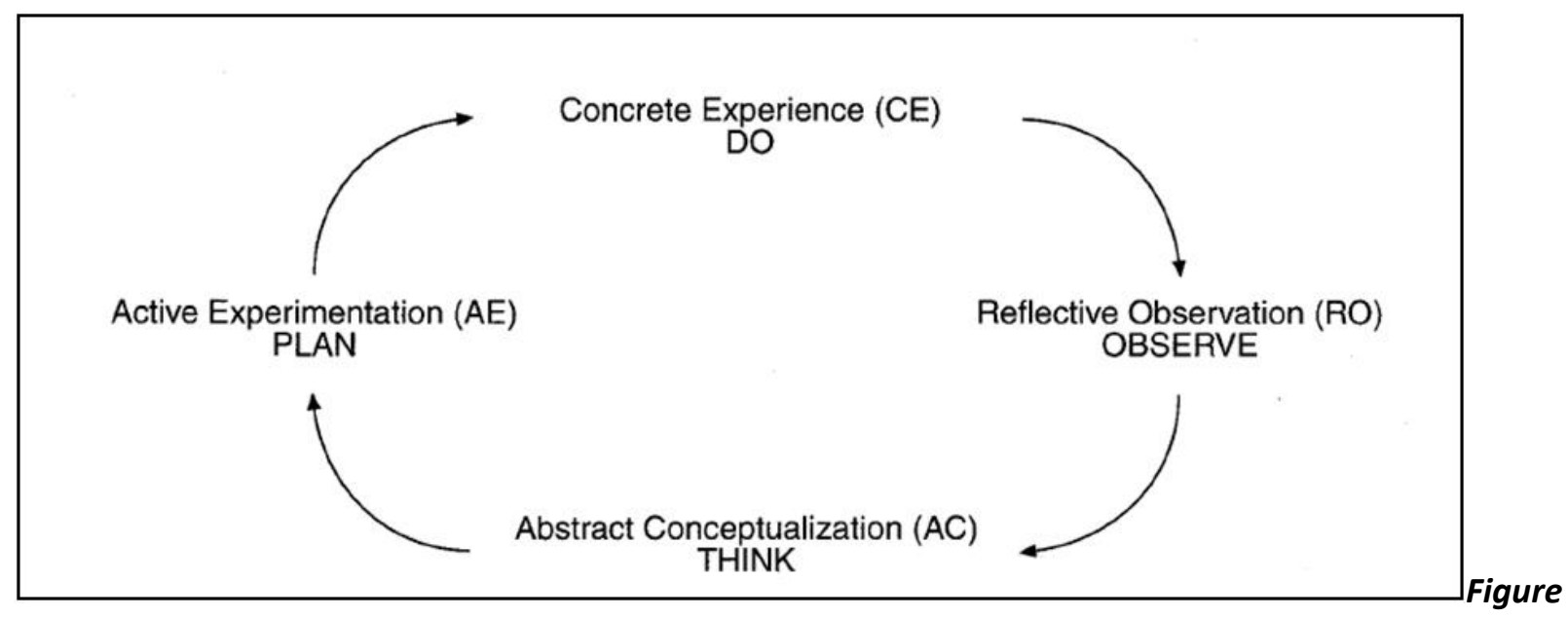

1: Kolb's Four Stage Experiential Learning Cycle. Adapted from Kolb (1984).

As directed by the Outward Bound Process (Walsh and Golins, 1976), Dewey (1938) and more specifically Kolb (1984), learning does not stem from the experience alone but rather the reflection upon this experience, ultimately leading to concepts that are tested through this active experimentation. Experiential education, which has previously been more specifically linked to challenge courses, tend to focus on experiences which develop personal learning such as increased self-esteem, positive risk-taking, self-concept and locus of control (Hattie et al., 1997; Gillis \& Speelman, 2008). Due to the goal dependent nature of individual programs the value of the outcomes is irrelevant, what it does bring about is the question of program design. A design must be incorporated where the outcomes of the curriculum based learning and the challenge course experience enhance and complement each other in addition to providing a sound comprehension of the curriculum alone.

This idea of integrating curriculum into experiences (i.e., curriculum based on experiences) is hinted at in Healey and Jenkin's (2000) paper outlining the application of Kolb's 
theory to geography in higher education. By using the four learning styles correspond with the four stages of Kolb's theory they outlined several geography curriculum based experiences that focused on enhanced comprehension. They also encouraged educators to re-think their approach to instruction so that they could be highly effective.

A long time debate among experiential educators is the level of involvement of facilitation outlined by James (1980) in his paper "Can the Mountains Speak for Themselves?". The question is whether participants should be left to their own devices to develop meaning from the experience, letting the mountains speak for themselves, or should facilitators coach and counsel them to uncover the meaning (1980)? James argues both techniques are beneficial as long as the design is deliberate. This deliberateness is necessary to elicit great effect from simple situations and tasks. Challenge course programming with the integration of specific educational curriculum is one such deliberate approach that's focuses on the facilitator as coach and counselor. Preliminary clarification and explanation of this approach has occurred with the Coalition for Christian Outreach's Models of Integration (MOI) @ (1999). Originally focused on faith-based integration, a broadening of the application of the model was outlined in a presentation by Harlan and Grout (2008) at the Association for Challenge Course Technology's Annual International Challenge Course Symposium and Conference. Four distinct levels of curriculum integration, non, pseudo, partial and holistic-integration were identified that are commonly adhered to in challenge course programs. Non-integration is characterized by high level of disconnect with the activity and the curriculum. The activity is seen as only a platform from which the curriculum can be presented. There is no attempt to front load the student's experience in regards to the curriculum that is to be covered. The information is 
disseminated via traditional lecture style approach providing no solicitation of student's

reflection on the experience (Harlan and Grout, 2008).

\section{Models of Academic Integration into Experiential Activities \\ Adapted from Paul Harbison's Models of Integration O CCO 1999}

\author{
Non Integrated
}

Characteristics:

Activity as a platform for the lesson.

$$
\text { Pseudo Integration }
$$

Characteristics:

Nomenclature is the primary connection between activity and curriculum.

Participants are left to make

The activity acts as an introduction to the topic. Learning does not stem from the activity, but from the presentation of content post-activity.

Typical Outcomes:

Participants receive the content in the traditional way and may even be distracted by the activity.

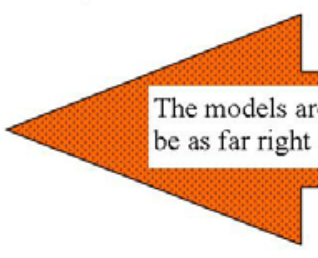

all connections on their own based on the name of the activity, with little help from the facilitator

\section{Typical Outcomes:}

Participants may or may not learn about the content of the lesson. Pre-conceived ideas about the content will be reenforced unless challenged by the facilitator and group.
Partial Integration

\section{Holistic Integration}

Characteristics:
The activity experientially
teaches the curriculum on a
limited level.
The activity and processing
teach at least one aspect of
the curriculum in an experien-
tial way, but may not provide
the opportunity for learning to
fully connect.

Characteristics:

The activity embodies the curriculum on multiple levels and is coupled with other teachings methods and styles.

The activity and processing create numerous isomorphic connections with the participants, creating imagery, motor sensory, and auditory linkages to the curriculum and the larger context of life.

Typical Outcomes:

Typical Outcomes:

Experientially taught content will be highlighted in the participants memory but may not be fully connected to other aspects of life.

The multiple isomorphic connections allow students to internalize curriculum, making them more likely to remember the content and internalize it.

Figure 2: Models of Academic Integration. Adapted from Harlan and Grout's 2008 presentation at ACCT's Annual International Challenge Course Symposium and Conference.

The next level is pseudo integration. It is differentiated from non-integration from its

use of a name to describe the activity or experience that is highly related to the curriculum. For

example a paired climbing event, in pseudo integration, would be presented to participants by

the name of teamwork tower, if the curriculum to be presented later pertained to key

characteristic to successful team work. The name is the only connection made between the

experience and the curriculum and the students are left to fill in the gaps between the distinct 
parts of the entire experience. The outcome for both of these would be similar to traditional lectures with the challenge course experience producing no added benefit or greater understanding of the subject matter.

Partial integration is characterized by creating a limited connection between the curriculum and the experience. The experience is explored and reflected upon in limited manner. Metaphors are touched on but not fully developed or applied to generality of the experience and curriculum by the group. Elevated learning occurs however no internalization of the content takes place. Only a superficial and fleeting connection is made between the active involvement and the theory and content of the curriculum. Ideally holistic integration is a thorough exploration and reflection of the experience with the additive content and tinted viewing glass of the curriculum. This produces a transfer of learning that becomes a new framework from which the experience continues. This newly created situation generates the opportunity to reexamine and implement elements of the curriculum as well as attempt mastery of key points of the curriculum. Both the activity and processing relies heavily on the use of metaphor to make motor sensory, auditory, and imagery links to the content and how it is applicable to the context of an individual's life (Harlan and Grout, 2008).

The concept of integration is something that most experiential educators strive for; however, there is limited research or guidelines on explicit tactics of how to incorporate curriculum and challenge course activities. The models of integration presented provide a framework for programs that desires guidelines to ensure the highest level of comprehension and internalization of a specific curriculum. Even with its roots in experiential learning theory 
there is a need to uncover support for challenge education program's continuous use of this framework.

\section{Challenge Course History}

The modern challenge (ropes) course in the large view is a rather young and still developing field. Surprisingly enough the basic roots of the design and outcomes hark back to the late $17^{\text {th }}$ century in the form of military obstacle courses (Rohnke, 1999. Despite this, the championed father of the modern experiential education and challenge courses is Kurt Han with his progressive survival training for British sailors during WWII (“Delivering Life Experiences", n.d.). Kurt Han in 1934 founded the Gordonstoun School in northern Scotland, which later became the Outward Bound School, with the aim of strengthening the character and intellect of young men ("Delivering Life Experiences", n.d.). Recognizing that young men were dying at sea due to lack of experience and confidence, a series of ropes and platforms were constructed at varying heights and used to simulate the physical and mental rigors of life at sea. These early challenge course constructions quickly became a vital part of the Outward Bound curriculum and experience, and as the constructions changed and developed so did the various approaches and uses.

Challenge courses made their debut in the US via the Colorado Outward Bound School in 1961 (Wagstaff, 2003). From their success within Outward Bound, challenge courses and their use expanded into the educational system with constructions at middle schools, high schools and even universities. There was a desire to bring the benefits of the Outward Bound process to mainstream education (Wagstaff, 2003). In attempting to produce the outcomes of a 26-day program in a much more condensed timeframe, the challenge course was seen as the 
most accessible part of the Outward Bound experience. Out of this concept, Project Adventure was created to provide students, mainly $10^{\text {th }}$ graders, with a new form of physical education as well as integration of areas of study (Wagstaff, 2003). Project Adventure's exposure of challenge courses to mainstream education, increased their presence (Wagstaff, 2003). By the 1980s more than 700 challenge course structures existed in the United States (Wagstaff, 2003). The number of structures exploded to nearly 15,000 by 2003 with practitioners finding more and more applicable uses for this challenge experience (Wagstaff, 2003).

Today applications of challenge course programming has been seen in therapeutic counselling, recreation programs, summer camps, conference centers, universities, corporate training organizations, and other educational programs. A large part of the expansion of this relatively new industry has been attributed to the many benefits and outcomes that can be elicited from participation. Even with large support, in order to promote this academic field there is a desire to validate the use of this learning process and experience beyond simply anecdotal evidence.

\section{Challenge Course Research}

As only one part of a rather young field of study challenge courses carry, up until recent, a level of uncertainty in their outcome effects (Gillis and Speelman, 2008). Research in experiential education and more specifically challenge course is still developing and evolving. Through the history and development it has been recognized that challenge courses have been applied to a wide range of settings for a variety of purposes. As challenge courses and their applications developed, it became apparent that practitioners and participants were observant of and receptive to the effects and outcomes produced. However, there is a question as to 
what the true benefits of challenge course experiences are, how they are developed, and what design characteristics would allow practitioners to ensure desired effects.

In their mean-end investigation Goldenberg et al.(2000) identified associated benefits with participation in a challenge course experience. Key outcomes identified by the participants included previously identified benefits of trust, teamwork, and communication as well as increased effectiveness, goal setting, developing understanding, and task accomplishment (Goldenberg et al., 2000). Focusing on more individual benefits, participants mentioned self-fulfilment, fun, and developing a sense accomplishment as prevalent outcomes (Goldenberg et al., 2000). Additional benefits as cited in other research include group cohesion, self-confidence, self-efficacy, self-esteem, academic self-esteem, risk taking propensity and locus of control (eg. Morris, 1987; Steffen and Cross, 1994; MacRae, Moore, Savage, Soehner and Priest, 1993; Gillis and Speelman, 2008). The majority of support for these outcomes are in the form of anecdotal and simple observation and have been accepted with very little empirical evidence. Several authors have remarked on the lack of research in support of challenge courses and their benefits (Rohnke et al., 2007; Martin, Cashel, Wagstaff and Breunig, 2006). In fact there are minimal offerings of statistical support published in peer-reviewed journals that lay the foundation for these claimed outcomes (Gillis and Speelman, 2008).

Gillis and Speelman's (2008) meta-analysis is a good benchmark for the quality of and level to which previous research has been conducted. They recognized that the majority of research has taken the form of unpublished thesis and dissertations. Initially 137 papers between 1986 and 2006 were identified. These were pared down further due to the parameters set forth by the authors. Studies were excluded from the analysis if they did not 
focus solely on challenge courses, utilize a control group or use quantitative measurements could produce an effect size. Therefore, only 44 papers were included in the analysis. Ten (10) distinct measured outcome categories, self-esteem or self-concept, self-efficacy, personality measures, behavioral observations, academic measures, environmental, attitudes about physical condition, family, physical variable, and group dynamics, were identified so that they could be compared. Study characteristics such as age, focus of program, length of program, activity used, and the type of control group were determined to further break down the analysis.

Typical of meta-analysis, the authors examined the effect size of studies to compare different treatments measured on different instruments. Coe (2002) concludes that "Effect size is a standardised, scalefree measure of the relative size of the effect of an intervention. It is particularly useful for quantifying effects measured on unfamiliar or arbitrary scales and for comparing the relative sizes of effects from different studies." (p.15). In order to be able to interpret the level of significance of an effect size Cohen uses familiar comparison while interpreting " $d$ " (Coe, 2002). Cohen categorized an effect size of $>.20$ as small, <.50 as medium and $<.80$ as large (Gillis \& Speelman, 2008). Cohen's categorization has been adopted as the standard interpretation for the social sciences. The highest effect size for outcomes were in the family construct, followed by group dynamics, attitudes about physical condition, and selfefficacy. An examination of self-esteem or self-concept construct uncovered that even though it has been the most investigated outcome, its effect size, 0.26 was nearly half of self-efficacy and attitudes of physical condition, nearly one third of group dynamics and only one fourth of the family construct effect size (Gillis and Speelman, 2008). 
A further break down by age groups showed adults as most receptive to the outcomes. The highest effect size was produced by studies conducted in therapeutic settings, when compared with developmental and educational focused settings. The length of programs producing the highest effect by far was between 21 and 30 hours of programming among all age categories. Activities that produced a medium effect included both high and low challenge courses, whereas studies with only low course exposure, or in which the activities could not be determined, produced a small which according to Wolf (1986) is an academically significant effect size. Among adults, therapeutic programming has a very large effect size of 1.20, whereas developmental programming retained a medium effect size. The lowest effect size when compared to all other groups was found to be among university students. Out of this particular category, only 1 study focused on educational settings, whereas 11 focused on developmental settings and 0 examined therapeutic applications (Gillis and Speelman). This demonstrates the lack of research on the educational and therapeutic focus of programming with university aged subjects. Several suggestions for the direction of further research were posed by Gillis and Speelman (2008). They noted that challenge course research should focus its efforts on outcomes that are significant, such as self-efficacy as opposed to continuing attempts to prove the benefits of low level outcomes like self-esteem. Additionally, specific characteristics of programs need to be examined more specifically in an attempt to flesh out their influence on outcomes.

Challenge course research focusing on college students has focused on a variety of outcomes such as self-esteem (Sung, 2004), locus of control (Boyle, 1986), problem solving skills (Breheny, 2000), self-concept (Sturdivant, 1991), self-efficacy (Witter, 2005) and group 
cohesion, group functioning, group and personal effectiveness (Hatch and McCarthy, 2005).

One study found that the use of a low ropes course was effective in developing and increasing a class's group functioning (processing skills) and trust, however uncertainty remained on whether group cohesion occurred during the study. This qualitative study questioning group cohesion as a valid outcome is contrary to other studies (e.g. Bell, 2006; Hatch and McCarthy, 2005; Glass and Benshoff, 2002) which have focused on group dynamics key concept of developing outdoor orientation program participant cohorts.

Barbara Witter (2004) attempted to explore the effects of facilitation techniques and their impact on generalizing college social self-efficacy beliefs. Focusing on the idea of framing and debriefing, she hypothesised that the cognitive restructuring of activities to that of a similar collegiate social setting will produce a greater effect as opposed to those who simply debriefed the activities. The author suggested that there was a design flaws in the recruitment process of the study. Students were solicited through flyers posting an opportunity to experience the ropes course. The author feared that this attracted an inaccurate representation the intended participant population. Examination of the self-efficacy measure produced only descriptive results and suggests exercising great caution when interpreting results. No noticeable difference was uncovered between the two approaches (debriefing only and frontloading plus debriefing) and so the focus of the study shifted toward an examination of whether a group can be developed in a one-time ropes course experience (Witter, 2004). Unable to truly use the result of the study, her dissertation focused on suggestions to eliminate any selection bias in order to produce results that can be generalized to a larger population. This further promotes the uses of a quasi-experimental design for further investigation. 
A second study focusing on college freshmen was Virginia Sturdivant's (1990) study examining the effects of a challenge course experience on subject's self-concept. The hypothesis that those exposed to the treatment of a challenge course experience would have a greater increase from pretest to post-test was not supported; however the logistic regression of the Platt Affective Behavior Scale identified perseverance, and expression of emotions and feelings as the differentiating scales. In addition to focusing on perseverance and emotion expression, Witter has written several similar considerations for future research. The study could be replicated with a larger sample size and the use of qualitative data to compliment quantitative. Sturdivant's final suggestion for future research was for the use of affective behaviors and skills in order to report individual sense of effectiveness as opposed to a selfreport designed instrument (1990).

Several other research studies examining challenge course's effects on a variety of selfefficacy constructs had mixed results. Nyhus, Napper-Owen and Phillips (1996) focused on college students and their general and task specific self-efficacy. Using a pretest, four post activity tests and follow up test, an evaluation of an eight-week adventure education class revealed that self-efficacy increased and was maintained for a moderate amount of time after the adventure experience (Nyhus et al., 1996). On the other hand, self-efficacy did not differ significantly between South African military career officers exposed to 3-day challenge course training and those exposed to traditional training methods (Stadler and Kotze, 2006). Several reasons for those results could be attributed to the military culture as well as discrepancy of age with the control group mean age two years older than the treatment group. Additionally 
no difference between control and experimental group was identified in measurement of selfconcept for many of the same confounding reasons as reported by Stadler and Kotze (2006).

\section{Self-efficacy}

“Perceived self-efficacy is defined as people's beliefs about their capabilities to produce designated levels of performance that exercise influence over events that affect their lives. Selfefficacy beliefs determine how people feel, think, motivate themselves and behave." (Bandura, 1994, p. 72) Some people face difficult tasks and situations as an opportunity to master skills and commit one's self whole-heartedly when they are self assured of their capabilities. Those who are doubtful in their abilities tend to fear difficult situation and challenges; this fear is usually manifested in avoidance, weak commitment to goals, and low aspirations (Bandura, 1994).

This belief in one's capabilities is not a static measure (Bandura, 1994). A person could have high perceived self-efficacy in regards to accomplishing one particular task and maintain a low level of perceived self-efficacy for another. The level of perceived self-efficacy one holds is task specific. It is an evaluation of one's perception of their capabilities deemed beneficial in producing a positive outcome of that particular task, challenge, or situation. A comparison is made between all the factors encompassing the task that are apparent to the person, weighed against their confidence in their ability in regard to successfully meeting all factors that are apparent (Bandura, 1997).

This is not to say that efficacy is merely task oriented or that one's efficacy cannot fluctuate in regards to a particular task. It is believed that, as humans, every one of us maintains a general level of perceived self-efficacy that is carried throughout every situation 
(Bandura, 1997). This is that basis of general regard for our capabilities to manage ourselves. This gives rise to our task specific perceived self-efficacy, which in turn can be brought back to the general perceived self-efficacy and be applied to a different situation (Bandura, 1997).

There may be a tendency in the challenge course and other mixed discipline fields to equate self-efficacy with self-esteem or even self-confidence. It is important to distinguish the differences. Self-esteem is one's evaluation of how one perceives themselves and the worth that they attach to themselves based upon that perception. Self-efficacy as previously explained is an evaluation of one's ability to accomplish a given task. This is to say that one could hold a high level of confidence in correctly completing complex algebraic equations (selfefficacy), and at the same time carry a low level of value or worth as a person (self-esteem). Even though it is independently developed and evaluated, whether or not someone is confident in accomplishing a given task can be used in evaluation of their self-esteem.

In general, perceived self-efficacy is capable of being developed. Bandura (1997) recognized several sources that cultivate self-efficacy beliefs, including enactive mastery experience, vicarious experience, verbal persuasion, as well as physical and emotional state. Working within the Walsh and Golins Outward Bound Process model, Sibthorp (2003) and McGowan (1986) both have further defined connections between adventure challenge education experiences and their ability to influence and promote the development of perceived self-efficacy. 


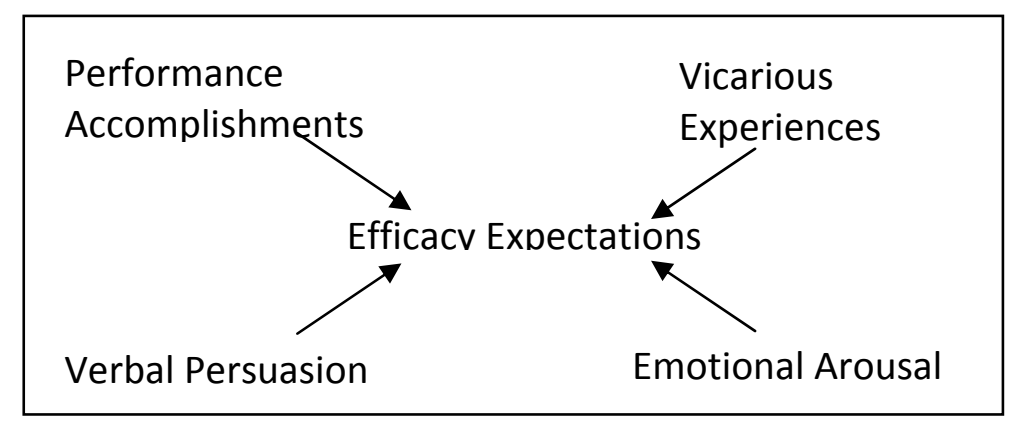

Figure 3: Four Sources of Perceived Self-efficacy. Adopted from Bandura (1977).

Performance accomplishment or mastery experience is the most influential source for the development of perceived self-efficacy. The participant is transplanted into a novel environment, both physically and socially, and presented with a problem. Their attempts lead to mastery of that particular situation, which develops into universally applicable learning. With mastery experiences developing from the individual, vicarious experiences are provided through the mastery attempts of fellow participants and the display of mastery by the instructor. Verbal persuasion is provided through the development of a supportive group environment which allows for the exchange of encouragement and feedback from all members. Lastly, that the novel environment, along with many social, physical and personal stressors, produces an emotionally involving experience which in turn contributes to levels of perceived risk (Sidthorp, 2003).

Maintaining a high level of perceived self-efficacy has been identified as a reliable predictor of success in areas including: achievement, career development, pain tolerance, physical education and sports, leisure and socialization (Collins, 1982; Feltz, 1982; Feltz and Mugno, 1983; Hackett and Betz, 19981; Hoff and Ellis, 1992; Litt, 1988; Schunk, 1984). Studies have shown that higher levels of perceived self-efficacy have a positive effect on both academic 
achievement as well as predicting likelihood of continued participation in adventure activities (Propst and Koesler, 1998; Sanders and Sanders, 1998).

Results of Hsieh, Sullivan, and Guerra's (2007) examination of the relationship of college attrition rates compared to students' level of self-efficacy and goal orientation reinforce this idea. Those students in the study with high levels of self-efficacy were more likely to achieve a higher level of goal mastery. In turn, the high level of both of these factors led to increased perseverance, value of one's effort, and higher achievement which leads to successful performance and ultimately graduation. The authors suggest that programs focused on selfefficacy of identifying adaptive and enabling beliefs and goal mastery will lead to greater levels of success. Examination of self-efficacy in this and other research settings has consistently been supported as a strong predictor of achievement (Bandura, 1997; Hsieh et al., 2007). However, even with this support, self-efficacy should be given more attention in regard to adventure education and it outcomes (Ewert, 1998, Hanns, 2000). 


\section{Method}

The focus of this study is to examine changes in perceived self-efficacy of first year college students participating in challenge course based pre-orientation programs. In this chapter the survey instruments utilized, experimental design and methods for data collection are outlined. A brief discussion of the analytical methods used to interpret the data is presented.

\section{Study Instrument}

\section{College Self-Efficacy Inventory-}

This inventory developed by Solberg, O'Brien, Villarreal, Kennel, and Davis (1993) measures students' confidence in accomplishing various college related tasks. Six independent experts voted on a pool of 40 items, of which 20 items received a high level of consensus. The 20 item were categorized further into 3 sub scales, roommate self-efficacy, course self-efficacy and social self-efficacy. Students are asked how confident they are that they could complete the following tasks and then allowed to rank their answer on a 9 point Likert-type scale form 0 (not at all confident) through 8 (very confident). Sample tasks include 'Talk with school academic and support staff', 'Write a good paper', 'Get along with others you live with', and 'Make new friends at college'.

Solberg et al.'s (1993) examination of the instrument construction indicates a high reliability as well as adequate validity (both convergent and discriminate). Additionally the instrument is not sensitive to cultural or gender differences. Due to this examination one of the 20 items was dropped from the instrument to 19. 


\section{College Academic Self-Efficacy Scale -}

This 33 item measure by Owen and Froman (1988) was constructed in much to the same manner as the CSEI. Three university faculty members developed a pool of college academics related items which were then pared down by 7 graduate teaching assistants. From here 93 undergraduate educational psychology students were given the items and asked to rank there importance in academic success on a 5 point Likert-type scale. All responses 3.0 and higher were retained resulting in a final 33 items. The measure was given to subjects who were asked to rank on a 5 point Likert-type scale ( 1 = very little to $5=$ quite a lot) how confident they are in performing the behavior listed. Such items focused on 'Participating in a class discussion', 'Making a professor respect you', Relating course content to material in other courses', and 'Taking essay tests'. Internal reliability and validity of all items were found to be adequate.

\section{Demographic survey -}

A simple survey to assess participants' demographic was developed in order to gain greater insight on participant characteristics. Subjects were asked to provide their gender, age, ethnic and home state. Individual responses to the four demographic questions were used to identify any significant differences in self-efficacy expectation based upon key characteristic groups.

The use of the above instruments allows for a unique examination of the program and curriculum. The CSEI is an overarching examination of a combination of both the social and academic dimensions of the college transition. Knowing that the program offers a unique opportunity for incoming first-year students to socialize this was used as validation for any perceived self-efficacy gain. The focus of the CASES is academically based. This instrument, a 
more in depth examination of academic tasks, allows for examination of the effects of the facilitation approach. Considering the University 101 curriculum is mostly academic based, the CASES would shed light on any influence the facilitation and curriculum presentation would have on the participants' perceived academic self-efficacy.

\section{Research Design}

This study was a quasi-experimental design whose subjects were West Virginia University first-year students enrolled in the Challenge Course Based pre-Orientation Program (ССBOP). In total 4 (out of 6 ) classes in the challenge course based program offered to the 2008 freshman class were chosen for the study. Since this was the first year of this program's operation, the first two courses were not included in the study and treated as an opportunity for facilitators to refine their skills. The 4 classes were randomly assigned one of two curriculum integration styles. Depending on the trip, study participants were exposed to either a 'Holistically integrated' curriculum design or “Non-integrated' curriculum design. Each group was exposed to the same core curriculum of University 101; however, the level of connection of the curriculum throughout the days' activities and the deliberate focus varied. The holistic integration sought to draw specific metaphorical connections to the activities and the curriculum. The dependent variable, self-efficacy, measured by the College Self-Efficacy Scale and the College Academic Self-Efficacy Scale, was assessed twice via a pretest/post-test design. This study design allowed for the examination of the program's effect on the self-efficacy of their students as well as measuring and identifying any differences between program designs.

The study was designated as quasi-experimental. The population chosen is not a true sampling of first year college students at WVU. Subjects are a sampling of first year students 
that chose to participate in Adventure West Virginia's odyssey programs. Certain other factors were also recognized as having bearing on who participated in the study. Some self-selecting occurred in the study with the participants choosing the class in which to enroll. Factors such as classes being filled or the first choice of class being full, not able to participate due to scheduling conflicts, or not able to pay the course fees or simply no interest in the program effected participation. However, classes were randomly assigned to the curriculum integration designs. This allowed for the closest of adherence to the experimental qualities of the study.

Figure 4 Treatment design

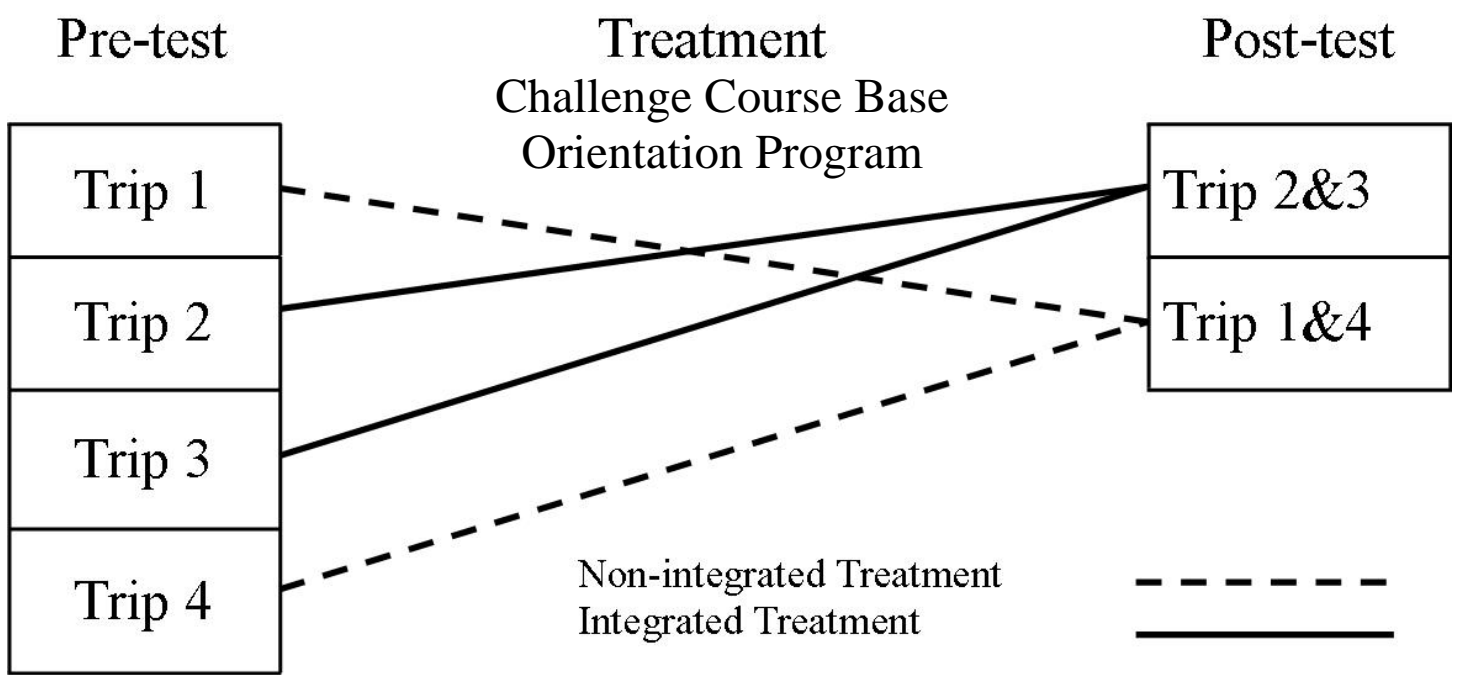

\section{Treatments}

All participants were exposed to one of two treatments. 'Holistically integrated' curriculum as outlined in previous section is an intentional focus on briefing, framing, frontloading and debriefing activities with the incorporation and exploration of a set curriculum. This facilitates a higher level of transference from insight achieved from the experience and its application to general or everyday life experiences. On the other end of the spectrum is the concept of 'Non-integrated' approach, in which the activity is distinctly 
separated from the curriculum. The activities are conducted in a traditional manner and afterward the curriculum is presented in a traditional lecture manner.

\section{Collection of Data}

Using the research design outlined in the previous section, data were collected in the summer of 2008 at 8 different times. The following outlines the method used for carrying out the pre-test and post-test data collection.

\section{Pre-test}

Solicitation for participation in the research study was conducted during the 'check-in' process. As students arrived on campus, registered with program leaders issued and deposited their gear they were asked to visit the researcher. At this time the study was explained to the participants, outlining that participation is voluntary, independent of Adventure West Virginia's requirements, and had no bearing on their course grade. It was also explained that participation or non-participation would be kept anonymous to the course instructors. The only alternative to participation is non-participation in the study. Those who decided to participate in the study completed the internal review board assent form and were then allowed ample time to complete the self-report instruments of the College Self-Efficacy Scale and the College Academic Self-Efficacy Scale. Upon the completion participants were free to rejoin their fellow students awaiting the start of the program.

\section{Post-test}

Post-test assessments were conducted in a similar manner to the pretest. After all trip gear was cleaned and returned, but prior to the closing ceremonies of the trip, participants 
were reminded of the research study and asked to revisit the researcher. Upon verbal confirmation of the participant's willingness to continue their voluntary participation, subjects were administered the College Self-Efficacy Scale and the College Academic Self-Efficacy Scale. Participants were again given ample time to complete the self-report instruments, and upon their completion asked to rejoin the group for the closing ceremonies. All research was conducted in compliance with WVU Institutional Review Board (IRB) and all data and vital information collected were managed according to IRB requirements. All surveys were administered and collected by the researcher.

\section{Data Analysis}

The raw data of the students' responses to the survey instruments were entered into SPSS 16. In order to identify any incomplete data sets descriptive statistics of all groups were computed. To maintain a high level of response but eliminating any potential for outliers, any data sets with more than three individual values missing on a single scale were eliminated from the study. This allowed the researcher to retain most data sets in order to maintain the highest number of survey responses. In total this produced 67 usable pretest as well as posttest data sets.

A paired t-test was used to compare the overall respondents' pre-test, post-test responses in order to gain an initial impression of the programs influence. Further examination was conducted via paired t-test of each scale by individual treatment group and independent sample t-tests between treatment groups' mean gain scores of each scale. 


\section{Results}

The focus of this study was to examine changes in perceived self-efficacy of first year college students participating in challenge course based pre-orientation programs (CCBOP). A quasi-experimental design was used to examine the research questions. The results of the study are outlined as follows: response rate, demographics, quantitative research question testing.

\section{Response Rate}

Pre-test - The pre-tests were conducted at the beginning of each individual program during the "check-in" process. All programs examined were made up of 22 incoming freshman. Out of the 22 students participating in each individual program, Odyssey ' $A$ ' ('Non-integrated'), fourteen students agreed to participate in the study, Odyssey 'B' ('Integrated') sixteen participants, Odyssey 'C' ('Integrated') twenty participants, and Odyssey 'D' ('Non-integrated') seventeen participants. This produced an initial response of 68 participants solicited for the study out of an available 88 (77.0\%). Individual response rates for treatment groups were 79.5\% for 'Non-integrated' and $70.0 \%$ for the 'Integrated' treatment group.

A total 30 of the College Self-Efficacy Scale surveys of the 'Non-integrated' treatment pretests were usable and 31 of the College Academic Self-Efficacy Scale. All 37 of the College SelfEfficacy Scale pre-tests for the 'Integrated' treatment groups were usable. However, 3 of the College Academic Self-Efficacy Scale responses were discarded due to multiple missing values.

Post-test - Sixty-seven (67) First Year Students of the 68 obtained for the study and who completed the pretest surveys were approached on the event's last day and prior to the 
conclusion of the program to complete the post-test survey. This led to an attrition rate of 1.5 $\%$ for the entire study and $4 \%$ in the 'Non-integrated' treatment group. In total only one College Self-Efficacy Scale posttest survey was discarded due to multiple missing values.

\section{Demographics}

A simple demographic survey was conducted along with the College Self-Efficacy Scale and the College Academic Self-Efficacy Scale. All Participants completed the four demographic questions specified below.

Gender- As anticipated, the breakdown of gender was nearly even (Figure 5). For the entire study 33 males (48.5\%) 35 females (51.5\%) participated. Further breakdown shows 14 males (45.0\%) and 17 females (55.0\%) for the 'Non-integrated' treatment group and 19 males (51.0\%) and 18 (49.0\%) females for the 'Integrated' treatment group. 


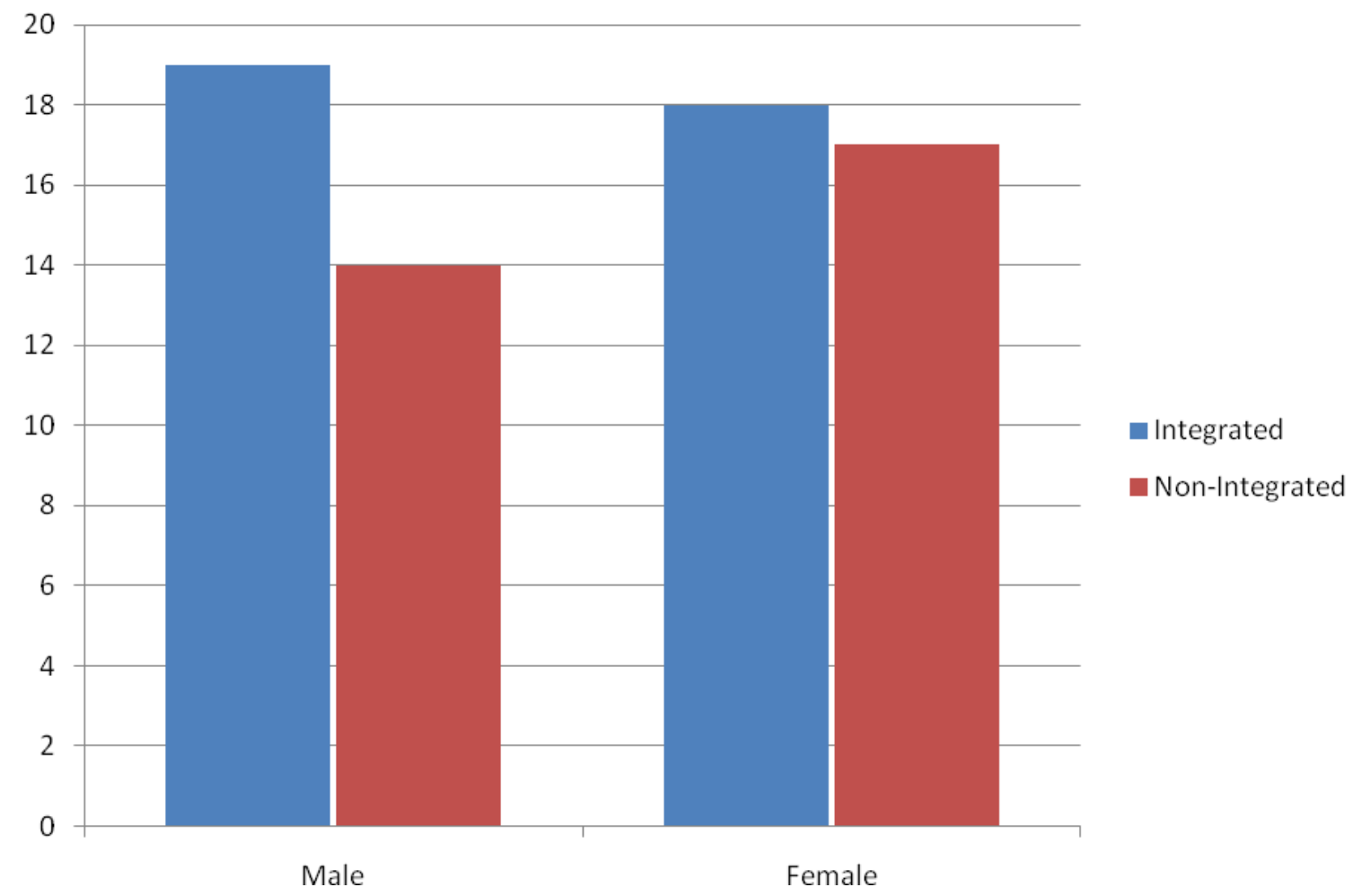

Figure 5: Gender distribution for 'Integrated' ( $n=37)$ and 'Non-integrated' (n=31) treatment groups participating in West Virginia University's 2008 СCBOP

Age - Participants, as anticipated, were either 17 or 18 years of age (Figure 6). The majority of respondents were 18 years of age (89.0\%). Of the 17 year old study respondents, 3 participated in the 'Integrated' treatment group and 4 particpated in the 'Non-integrated' treatment group. 


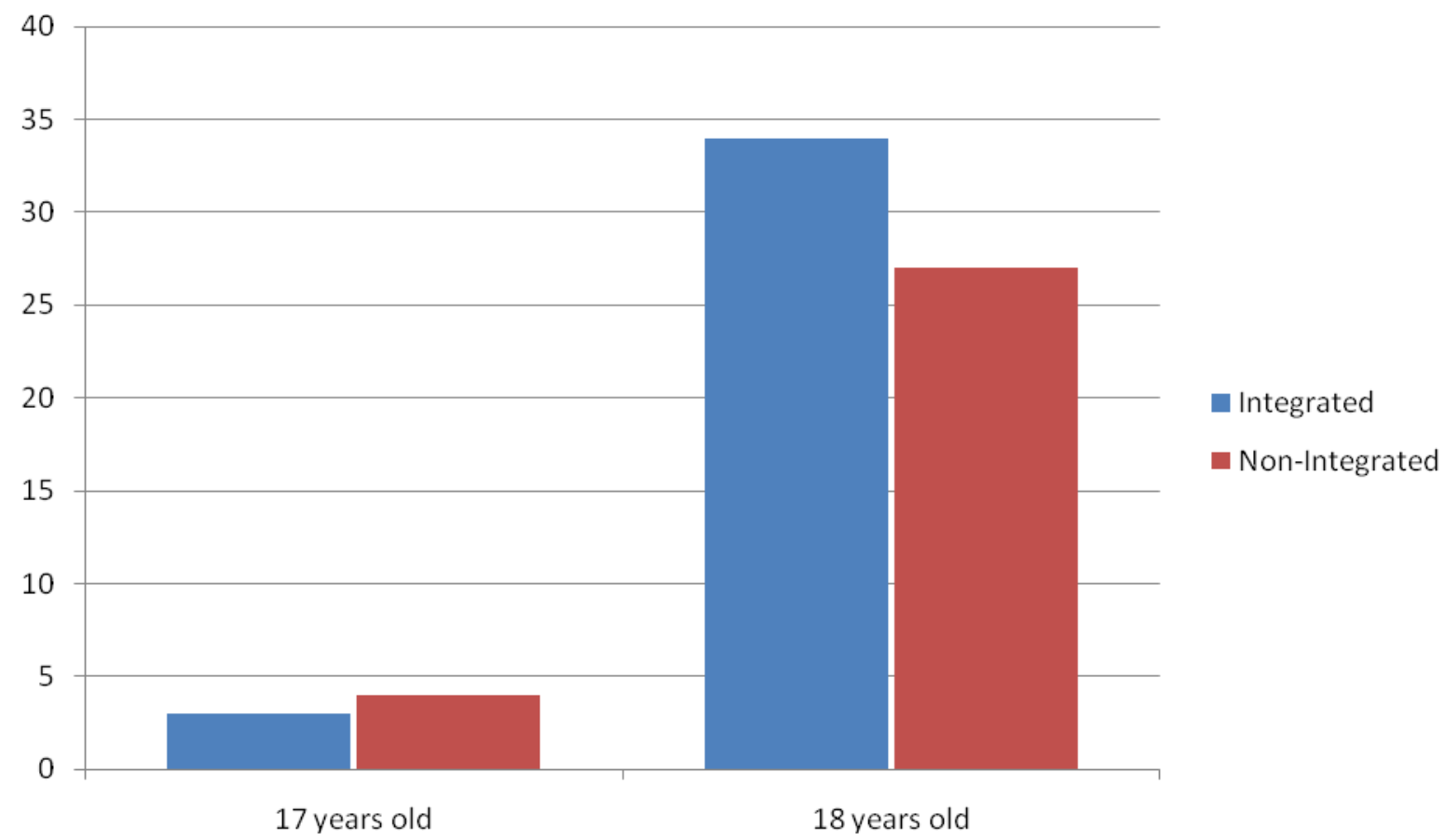

Figure 6: Age distribution for 'Integrated' ( $n=37)$ and 'Non-integrated' (n=31) treatment groups participating in West Virginia University's 2008 CCBOP

Ethnicity- The majority of participants identified themselves as being Caucasian (63 Participants, 92.0\%) (Figure 7). Three participants identified themselves as African-American (4.8\%), and 2 as Hispanic (2.9\%). Of the 'Integrated' treatment group, $97.3 \%$ considered themselves Caucasian. There were fewer Caucasians in the 'Non-integrated' treatment group (87.0\%). Ten percent of the 'Non-integrated' participants were African American. 


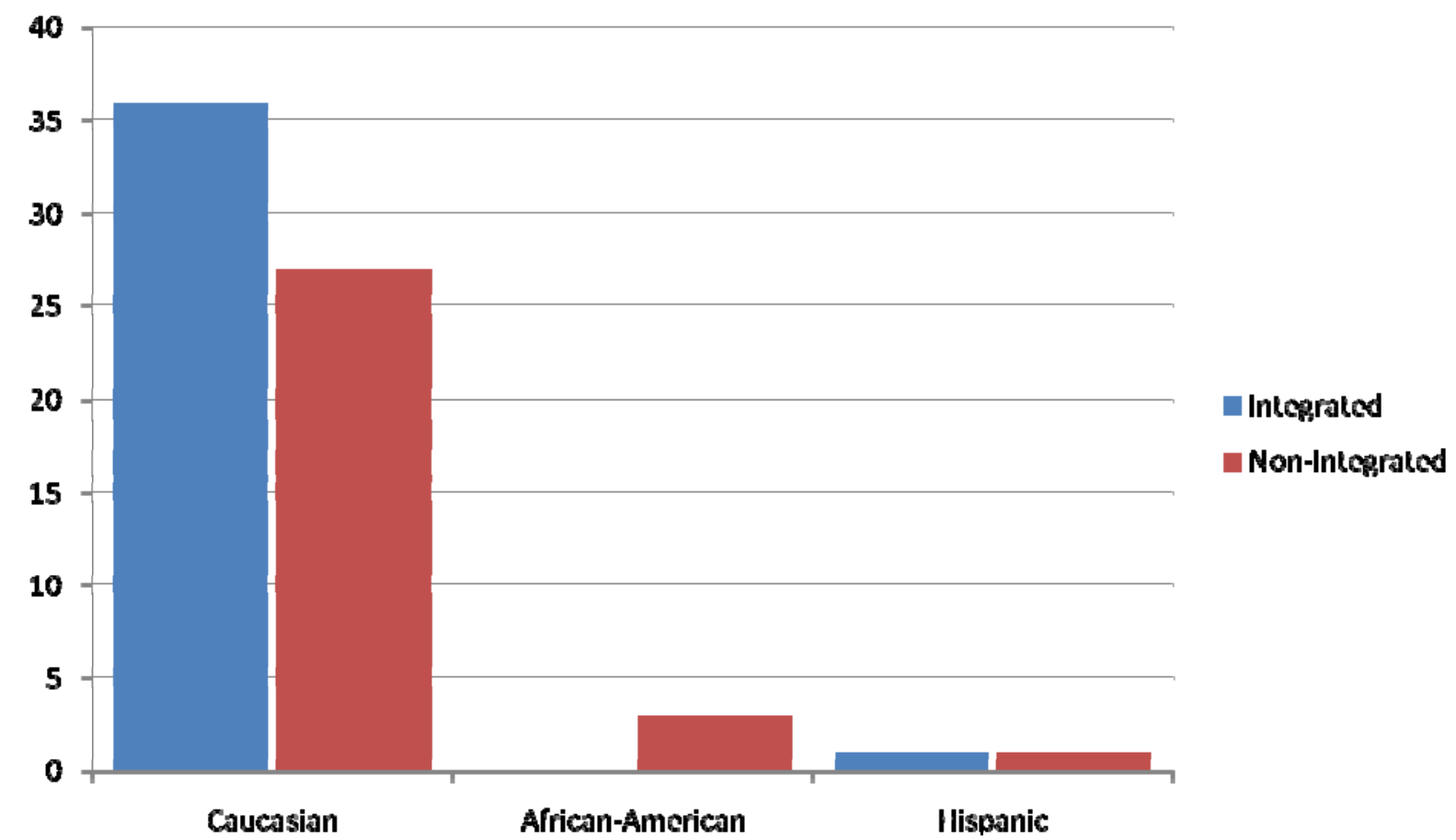

Figure 7: Ethnicity distribution for 'Integrated' ( $n=37)$ and 'Non-integrated' ( $n=31)$ treatment groups participating in West Virginia University's 2008 ССВОP

Home State - Research participants as indicative of nearly all higher education institutes were from a wide range of states (Figure 8). The highest majority of participants were from West Virginia (28.0\%). The 3 other states most often reported included Virginia (17.6\%), Maryland (13.2\%) and Pennsylvania (13.2\%) - 44\% of all study participants. New Jersey $(11.7 \%)$ is the only other majority from a state not adjacent to West Virginia. Three or fewer participants claim Delaware (4.4\%), New York (4.4\%), Ohio (3.0\%), Georgia (1.5\%), New Hampshire (1.5\%) or Texas (1.5\%) as their home state. 


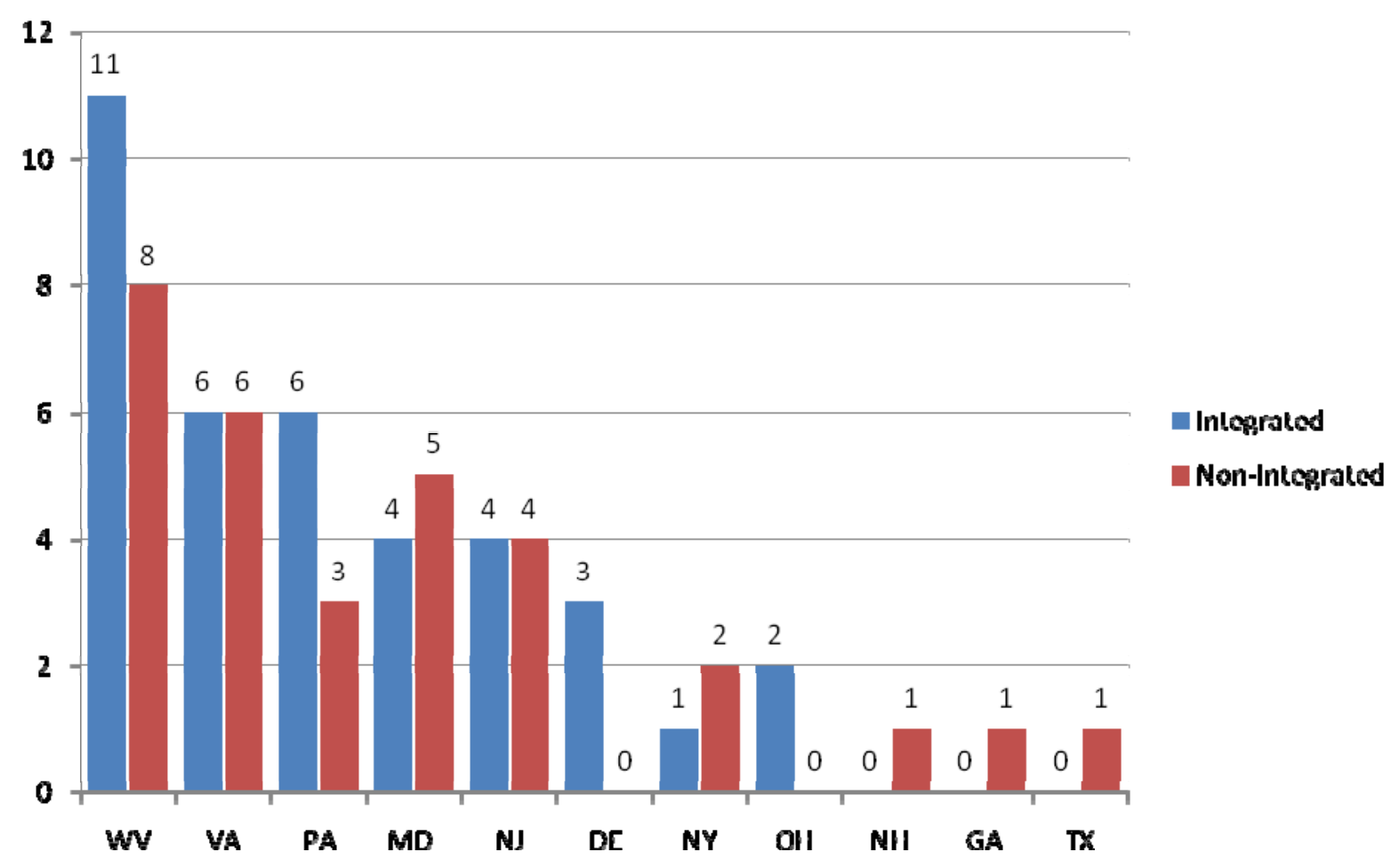

Figure 8. Residency distribution for 'Integrated' ( $n=37)$ and 'Non-integrated' ( $n=31)$ treatment groups participating in West Virginia University's 2008 CCBOP

Summary of Demographic Analysis - A comparison of the above mentioned demographics between each treatment group highlights an overall even distribution. As expected the division by gender was relativly balanced as the deisign of the program intended. The Integreated treatment group consisted of $6.0 \%$ more females than the Non-integreated and the inverse for the males. Not suprsisingly the treatment groups were made up of nearly all 18 year olds ('Integrated' $=92 \%$, 'Non-integrated' $=87 \%)$. Another overwhleming characteristic of the sample population was with a high majority of the partcipants being caucasian ('Integrated' = $97 \%$, 'Non-integrated' $=87 \%)$. The observation of $28 \%$ of the participants are from West Virginia, $47 \%$ from adacent states, and $25 \%$ are from all other states that closely parrall the distribution observed in the greater University population. 


\section{CSEI and CASES}

In order to examine the overall effectiveness of the program on students anticipated self-efficacy a paired t-test was conducted for all responses to the CSEI and CASES. Mean posttest scores were greater than pre-test scores for all items examined (Table 1). This pre-test post-test comparison among the CSEI responses resulted in statistically significant differences among all nineteen items ( $p$-value $\leq .05$, two-tailed). Seventeen of the 19 items were significantly different when alpha=.01 was used in the analysis ("Write a course paper" $p=.039$, "Socialize with others you live with" $p=.016)$. These two items as well as "Keep up to date with your school work' produced 'medium' effect size $(d \geq .50)$, whereas all the rest of the instrument produced 'large' effect sizes $(\mathrm{d} \geq .80)$

CASES paired t-test results (Table 2) of all subjects pre -test and post -test responses produced 29 items with a significant difference at a $p$-value of $p \leq .05$ (two tailed). Four individual items responses did not significantly differ among pre and post tests: 'Attending class regularly'( $p=.199)$, 'Attending class consistently in a dull course' $(p=.185)$, 'Performing simple math computations' $(p=.063)$, and 'Using a computer' $(p=.495)$.

Effect size for this survey are 3 items with 'small', 6 'medium', 23 'large' and one negative (Table 2). The item focused on 'Using a computer' produced an effect size of $d=-0.17$ indicating that the post-test scores dropped after subjects participated in the CCBOP. The statements which produced a small effect size are 'Attending class regularly', 'Attending class consistently in a dull course', 'Mastering most content in a math course'. The items effect size reiterates the t-test $p$-values highlighted in the previous paragraph. 
Table 1 Comparison between pre and post test responses to College Self-Efficacy Inventory

\begin{tabular}{|c|c|c|c|c|}
\hline College Self-Efficacy Inventory & $\mathbf{t}$ & df & $\begin{array}{l}\text { Sig. (2- } \\
\text { tailed) }\end{array}$ & $\begin{array}{c}\text { Effect } \\
\text { Size }\end{array}$ \\
\hline \multicolumn{5}{|l|}{ Social self Efficacy } \\
\hline Make new friends at college & -5.87 & 66 & $\leq .001 * *$ & 1.45 \\
\hline Talk to your professor/instructor & -7.06 & 66 & $\leq .001 * *$ & 1.74 \\
\hline Ask a professor or instructor a question outside of class & -5.73 & 65 & $\leq .001 * *$ & 1.42 \\
\hline Talk with a school academic and support staff & -6.43 & 65 & $\leq .001 * *$ & 1.60 \\
\hline Ask a question in class & -5.33 & 66 & $\leq .001 * *$ & 1.31 \\
\hline Participate in class discussions & -5.75 & 66 & $\leq .001 * *$ & 1.42 \\
\hline Get a date when you want one & -5.61 & 64 & $\leq .001 * *$ & 1.40 \\
\hline Join a student organization & -6.48 & 66 & $\leq .001 * *$ & 1.60 \\
\hline \multicolumn{5}{|l|}{ Course Self-Efficacy } \\
\hline Take good class notes & -5.58 & 66 & $\leq .001 * *$ & 1.38 \\
\hline Research a term paper & -4.22 & 65 & $\leq .001 * *$ & 1.05 \\
\hline Understand your textbook & -5.82 & 66 & $\leq .001 * *$ & 1.43 \\
\hline Write a course paper & -2.11 & 66 & $.039 *$ & 0.52 \\
\hline Do well on your exams & -6.52 & 66 & $\leq .001 * *$ & 1.61 \\
\hline Manage your time effectively & -6.88 & 66 & $\leq .001 * *$ & 1.69 \\
\hline Keep up to date with your school work & -3.13 & 66 & $.003 *$ & 0.77 \\
\hline \multicolumn{5}{|l|}{ Roommate Self-Efficacy } \\
\hline Divide chores with others you live with & -5.43 & 65 & $\leq .001 * *$ & 1.35 \\
\hline Get along with other you live with & -3.89 & 65 & $\leq .001 * *$ & 0.97 \\
\hline Socialize with others you live with & -2.46 & 66 & $.016 *$ & 0.61 \\
\hline Divide space in your residence (if applicable) & -6.09 & 58 & $\leq .001 * *$ & 1.60 \\
\hline
\end{tabular}

*Paired t-test, two-tail $\mathrm{p} \leq .05$

**Paired t-test, two-tail $p \leq .01$ 
Table 2 Comparison between pre and post test responses to Academic Self-Efficacy Survey

\begin{tabular}{|c|c|c|c|c|}
\hline College Academic Self-Efficacy Scale & $\mathbf{t}$ & Df & $\begin{array}{l}\text { Sig. (2- } \\
\text { tailed }\end{array}$ & $\begin{array}{c}\text { Effect } \\
\text { Size }\end{array}$ \\
\hline Taking well-organized notes during a lecture & -3.89 & 66 & $\leq .001 * *$ & 0.96 \\
\hline Participating in class a discussion & -5.84 & 66 & $\leq .001 * *$ & 1.44 \\
\hline Answering a question in a large class & -5.33 & 66 & $\leq .001 * *$ & 1.31 \\
\hline Answering a question in a small class & -4.58 & 66 & $\leq .001 * *$ & 1.13 \\
\hline Taking "objective" tests (multiple-choice, T-F, matching) & -3.07 & 66 & $.003 *$ & 0.76 \\
\hline Taking essay tests & -3.26 & 66 & $.002 *$ & 0.80 \\
\hline Writing a high quality term paper & -4.37 & 66 & $\leq .001 * *$ & 1.08 \\
\hline Listen carefully during a lecture on a difficult topic & -3.84 & 66 & $\leq .001 * *$ & 0.95 \\
\hline Tutoring another student & -5.83 & 65 & $\leq .001 * *$ & 1.45 \\
\hline Explaining a concept to another student & -3.79 & 65 & $\leq .001 * *$ & 0.94 \\
\hline Asking a professor in class to review a concept you don't understand & -6.25 & 65 & $\leq .001 * *$ & 1.55 \\
\hline Earning good marks in most courses & -2.79 & 64 & $.007^{*}$ & 0.70 \\
\hline Studying enough to understand content thoroughly & -3.98 & 65 & $\leq .001 * *$ & 0.99 \\
\hline Running for student government office & -4.38 & 65 & $\leq .001 * *$ & 1.09 \\
\hline Participating in extracurricular events (sports, clubs) & -5.09 & 64 & $\leq .001 * *$ & 1.27 \\
\hline Making professors respect you & -2.64 & 64 & $.010 *$ & 0.66 \\
\hline Attending class regularly & -1.29 & 65 & .199 & 0.32 \\
\hline Attending class consistently in a dull course & -1.34 & 63 & .185 & 0.34 \\
\hline Make a professor think you're paying attention in class & -2.41 & 64 & $.018^{*}$ & 0.60 \\
\hline Understanding most ideas you read in you tests & -3.36 & 65 & $.001 *$ & 0.84 \\
\hline Understanding most ideas presented in class & -3.82 & 64 & $\leq .001 * *$ & 0.96 \\
\hline Performing simple math computations & -1.89 & 65 & .063 & 0.47 \\
\hline Using a computer & 0.68 & 65 & .495 & 0.17 \\
\hline Mastering most content in a math course & -2.30 & 65 & $.024 *$ & 0.57 \\
\hline Talking to a professor privately to get to know him or her & -6.24 & 65 & $\leq .001 * *$ & 1.55 \\
\hline Relating course content to materials in other courses & -5.24 & 63 & $\leq .001 * *$ & 1.32 \\
\hline Challenging a professor's opinion in class & -4.14 & 65 & $\leq .001 * *$ & 1.03 \\
\hline Applying lecture content to a laboratory session & -4.93 & 65 & $\leq .001 * *$ & 1.22 \\
\hline Making good use of the library & -8.12 & 65 & $\leq .001 * *$ & 2.01 \\
\hline Getting good grades & -2.42 & 65 & $.018^{*}$ & 0.60 \\
\hline Spreading out studying instead of cramming & -6.37 & 65 & $\leq .001 * *$ & 1.58 \\
\hline Understanding difficult passages in textbooks & -6.53 & 65 & $\leq .001 * *$ & 1.62 \\
\hline Mastering content in a course you're not interested in & -3.70 & 64 & $\leq .001 * *$ & 0.93 \\
\hline
\end{tabular}

*Paired t-test, two-tail $p \leq .05$

**Paired t-test, two-tail $p \leq .01$ 


\section{Treatment Group CSEI Paired t-test Comparison}

Responses to 15 CSEI scales significantly differed (paired t-test, two-tailed $p<.01$ ) between pre and post tests among both treatment groups (Table 3). All eight Social SelfEfficacy variables were significant in both treatment groups ('Make new friends at college', 'Get a date when you want one', Joining as student organization', 'Talk to your professor/instructor', 'Ask a professor or instructor a question outside of class', 'Talk with a school academic and support staff', 'Ask a question in class', 'Participate in class discussions' ). In the Course Self-Efficacy subcategory all 'Non-integrated' treatment group values were found to be significant except for students' confidence in their ability to 'Write a course paper' $(p=$ $.203)$.

The 'Integrated' treatment group's pair wise t-test results produced statistically significant values except the items regarding students' confidence in their ability to 'Write a course paper' ( $p=.102)$, as well as 'Keep up to date with school work' $(p=.151)$ (Table 3). Examination of the smaller subcategory of Roommate Self-Efficacy showed the 'Non-integrated' treatment group to have three statistically significant values ('Divide chores with others you live with', 'Get along with others you live with', 'Divide space in your residence (if applicable)'). Students' confidence pertaining to the item 'Socialize with others you live with' did not differ significantly $(p=.110)$ between pre and post tests.

The 'Integrated' treatment group produced statistical significance within two of the four items in the Roommate Self-Efficacy subcategory ('Divide chores with others you live with', 'Divide space in your residence (if applicable)') (Table 3). Although approaching significance, no 
differences were identified when examining pretest and posttest responses for 'Socialize with others you live with' $(p=.076)$ and 'Get along with others you live with' $(p=.09)$.

Effect sizes were 'large' for the 'Integrated' and 'Non-integrated' groups within the Social self-efficacy subscale (Table 3). Not surprisingly the effects size of items whose responses which failed to produce statistical significance produced smaller effect size. In support of the test for statistical significance, the 'Integrated' group, produced two individual 'small' and 'medium' effect sizes. Response to the item, 'Keep up to date with your school work', for the 'Non-integrated' group produced a small effect size $(d=.49)$ which has educational significance (Wolf, 1986) however is still lower than the 'Integrated' group which saw a 'large' effect $(\mathrm{d}=1.14)$. Responses to a second item produced a 'medium' effect among both treatment groups ('Socialize with others you live with', 'Non-integrated' $d=.61$, 'Integrated' $d=.61$ ). The ability to 'Write a course paper', produced a 'small' effect size in the 'Non-integrated' treatment $(d=.48)$ and 'medium' $(d=.56)$ among the 'Integrated'. The last effect size difference is see in responses to the item concerned with 'Get along with other you live with', where the 'Integrated' group's effect size is 'medium' ( $d=.58)$ and the 'Nonintegrated' is 'large' with d equal to 1.59. 
Table 3 Comparison between pre and post test responses to College Self-Efficacy Inventory by treatment group.

\begin{tabular}{|c|c|c|c|c|c|c|c|c|}
\hline \multirow[b]{2}{*}{ College Self-Efficacy Inventory } & \multicolumn{3}{|c|}{$\begin{array}{l}\text { 'Non-integrated' } \\
\text { Treatment Group }\end{array}$} & \multicolumn{5}{|c|}{$\begin{array}{c}\text { 'Integrated' } \\
\text { Treatment Group }\end{array}$} \\
\hline & $\mathbf{t}$ & df & $\begin{array}{l}\text { Sig. (2- } \\
\text { tailed) }\end{array}$ & $\begin{array}{l}\text { Effect } \\
\text { Size }\end{array}$ & $\mathbf{T}$ & df & $\begin{array}{l}\text { Sig. (2- } \\
\text { tailed) }\end{array}$ & $\begin{array}{c}\text { Effect } \\
\text { Size }\end{array}$ \\
\hline \multicolumn{9}{|l|}{ Social self Efficacy } \\
\hline Talk to your professor/instructor & -5.95 & 29 & $\leq .001 * *$ & 2.21 & -4.28 & 36 & $\leq .001 * *$ & 1.43 \\
\hline Ask a professor or instructor a question outside of class & -4.25 & 29 & $\leq .001 * *$ & 1.58 & -3.90 & 35 & $\leq .001 * *$ & 1.32 \\
\hline Talk with a school academic and support staff & -5.87 & 28 & $\leq .001 * *$ & 2.22 & -3.80 & 36 & $.001 *$ & 1.27 \\
\hline Ask a question in class & -4.48 & 29 & $\leq .001 * *$ & 1.66 & -3.25 & 36 & $.003 *$ & 1.08 \\
\hline Participate in class discussions & -4.33 & 29 & $\leq .001 * *$ & 1.61 & -3.91 & 36 & $\leq .001 * *$ & 1.30 \\
\hline Make new friends at college & -5.11 & 29 & $\leq .001 * *$ & 1.90 & -3.53 & 36 & $.001 *$ & 1.18 \\
\hline Get a date when you want one & -4.00 & 28 & $\leq .001 * *$ & 1.51 & -3.98 & 35 & $\leq .001 * *$ & 1.35 \\
\hline Join a student organization & -4.43 & 29 & $\leq .001 * *$ & 1.65 & -4.96 & 36 & $\leq .001 * *$ & 1.65 \\
\hline \multicolumn{9}{|l|}{ Course Self-Efficacy } \\
\hline Take good class notes & -4.44 & 29 & $\leq .001 * *$ & 1.65 & -3.51 & 36 & $.001 *$ & 1.17 \\
\hline Research a term paper & -3.09 & 28 & $.004 *$ & 1.17 & -2.86 & 36 & $.007^{*}$ & 0.95 \\
\hline Understand your textbook & -3.84 & 29 & $.001 *$ & 1.43 & -4.40 & 36 & $\leq .001 * *$ & 1.47 \\
\hline Write a course paper & -1.30 & 29 & .203 & 0.48 & -1.67 & 36 & .102 & 0.56 \\
\hline Do well on your exams & -3.91 & 29 & $.001 *$ & 1.45 & -5.25 & 36 & $\leq .001 * *$ & 1.75 \\
\hline Manage your time effectively & -5.25 & 29 & $\leq .001 * *$ & 1.95 & -4.51 & 36 & $\leq .001 * *$ & 1.50 \\
\hline Keep up to date with your school work & -3.07 & 29 & $.005^{*}$ & 1.14 & -1.46 & 36 & .151 & 0.49 \\
\hline \multicolumn{9}{|l|}{ Roommate Self-Efficacy } \\
\hline Divide chores with others you live with & -3.35 & 28 & $.002 *$ & 1.27 & -4.25 & 36 & $\leq .001 * *$ & 1.42 \\
\hline Get along with other you live with & -4.21 & 28 & $\leq .001 * *$ & 1.59 & -1.74 & 36 & .090 & 0.58 \\
\hline Socialize with others you live with & -1.64 & 29 & .110 & 0.61 & -1.82 & 36 & .076 & 0.61 \\
\hline Divide space in your residence (if applicable) & -4.22 & 24 & $\leq .001 * *$ & 1.72 & -4.59 & 33 & $\leq .001 * *$ & 1.60 \\
\hline
\end{tabular}

*Paired t-test, two-tail $\mathrm{p} \leq .05$

$* *$ Paired t-test, two-tail $p \leq .01$ 


\section{Treatment Group CASES Paired t-test Comparison}

Most of the CASES pre and post test responses provided by both the "Non-integrated' and 'Integrated' groups were significantly different (paired t-test, two-tailed $p<.05$ ) (Table 4). For example, students in the 'Non-integrated' treatment group responded with a higher level of confidence on the post test on such items as, 'Spreading out studying instead of cramming' ( $p \leq .001)$, 'Master content in a course you're not interested in' ( $p \leq .001)$, 'Understanding difficult passages in textbooks' ( $p \leq .001)$, 'Challenging a professor's opinion in class' ( $p \leq .001)$, 'Applying lecture content to a laboratory session' ( $p \leq .001)$, 'Participating in extracurricular events (sports, clubs)' ( $p \leq .001)$, 'Participating in class a discussion" ( $p \leq .001)$, 'Asking a professor in class to review a concept you don't understand' ( $p \leq .001)$, 'Answering a question in a large class' $(p \leq .001)$.

Pre and post test responses of the 'Integrated' treatment group were significantly different (pair wise t-test, $p<.01$ ) for 24 of the 33 CASES items examined (Table 4). Comparison of the responses of those students exposed to the 'Integrated' treatment were most significant on items such as: 'Taking well-organized notes during a lecture' ( $p \leq .001)$, 'Participating in a class discussion' ( $p \leq .001)$, 'Answering a question in a small class' $(p<.000)$, 'Writing a high quality term paper' ( $p \leq .001)$, 'Listen carefully during a lecture on a difficult topic' $(p \leq .001)$, 'Tutoring another student' ( $p \leq .001)$, 'Asking a professor in class to review a concept you don't understand' ( $p \leq .001)$, 'Running for student government office' ( $p \leq .001)$, 'Understanding most ideas you read in your tests' $(p \leq .001)$, 'Understanding most ideas presented in class' $(p \leq .001)$, 'Talking to a professor privately to get to know him or her' ( $p \leq .001)$, 'Relating course content to materials in other courses' ( $p \leq .001)$, 'Making good use of the library' ( $p \leq .001)$, 'Spreading out 
studying instead of cramming' ( $p \leq .001)$, and 'Understanding difficult passages in textbooks' $(p \leq .001)$. Between both treatment groups, responses to four (4) items produced no significant difference from the pre-test and post-test: 'Attending class regularly', 'Make a professor think you're paying attention in class', 'Performing simple math computations', 'Using a computer'.

Examinations of the two treatment groups' responses to 23 items have a 'large' effect size ( $d \geq 0.8)$ for the 'Integrated' treatment group (according to Cohen's $d$ ) whereas the 'Nonintegrated' treatment group had a collective 16 items with a larger effect size (Table 4). Twelve of all the items with 'large' effect size were shared between each group. The effect size for the item 'Getting good grades' among 'Integrated' treatment group responses seen to be 'large' ( $d=1.08349)$, were as the 'Non-integrated' group produced an effect size of $d=.088$. A second statement produced the same difference with the item 'Mastering most content in a math course' with the 'Integrated' group's effect size of $d=1.09$ and the 'Non-integrated' group's $d=$ .000. The opposite of the previous relationship is seen with the one 'Non-integrated' group items effect size. 'Attending class consistently in a dull course' had a large effect size $(d=0.84)$ for 'Non-integrated' treatment group whereas the 'Integrated' treatment group's was much lower $(d=0.13)$. 
Table 4 Comparison between pre and post test responses to Academic Self-Efficacy Survey by treatment group.

\begin{tabular}{|c|c|c|c|c|c|c|c|c|}
\hline \multirow[b]{2}{*}{ Academic Self-Efficacy Survey } & \multicolumn{3}{|c|}{ 'Non-integrated' } & \multicolumn{5}{|c|}{ 'Integrated' } \\
\hline & $\mathbf{t}$ & df & $\begin{array}{l}\text { Sig. (2- } \\
\text { tailed) }\end{array}$ & $\begin{array}{l}\text { Effect } \\
\text { Size }\end{array}$ & $\mathbf{t}$ & df & $\begin{array}{l}\text { Sig. (2- } \\
\text { tailed) }\end{array}$ & $\begin{array}{l}\text { Effect } \\
\text { Size }\end{array}$ \\
\hline Taking well-organized notes during a lecture & -1.42 & 29 & .165 & 0.53 & -4.27 & 36 & $\leq .001 * *$ & 1.42 \\
\hline Participating in a class discussion & -4.26 & 29 & $\leq .001 * *$ & 1.58 & -4.09 & 36 & $\leq .001 * *$ & 1.36 \\
\hline Answering a question in a large class & -4.39 & 29 & $\leq .001 * *$ & 1.63 & -3.23 & 36 & $.003^{*}$ & 1.08 \\
\hline Answering a question in a small class & -2.11 & 29 & $.043 *$ & 0.78 & -4.27 & 36 & $\leq .001 * *$ & 1.42 \\
\hline Taking "objective" tests (multiple-choice, T-F, matching) & -1.75 & 29 & .090 & 0.65 & -2.51 & 36 & $.016 *$ & 0.84 \\
\hline Taking essay tests & -1.16 & 29 & .255 & 0.43 & -3.37 & 36 & $.002 *$ & 1.13 \\
\hline Writing a high quality term paper & -1.65 & 29 & .109 & 0.61 & -4.51 & 36 & $\leq .001 * *$ & 1.50 \\
\hline Listen carefully during a lecture on a difficult topic & -1.56 & 29 & .129 & 0.58 & -3.85 & 36 & $\leq .001 * *$ & 1.28 \\
\hline Tutoring another student & -2.73 & 28 & $.011 *$ & 1.03 & -5.79 & 36 & $\leq .001 * *$ & 1.93 \\
\hline Explaining a concept to another student & -1.79 & 29 & .083 & 0.67 & -3.55 & 35 & $.001 *$ & 1.20 \\
\hline $\begin{array}{l}\text { Asking a professor in class to review a concept you don't } \\
\text { understand }\end{array}$ & -4.33 & 29 & $\leq .001 * *$ & 1.61 & -4.56 & 35 & $\leq .001 * *$ & 1.54 \\
\hline Earning good marks in most courses & -2.19 & 28 & $.036 *$ & 0.83 & -1.75 & 35 & .088 & 0.59 \\
\hline Studying enough to understand content thoroughly & -2.98 & 29 & $.006 *$ & 1.11 & -2.64 & 35 & $.012 *$ & 0.89 \\
\hline Running for student government office & -1.72 & 29 & .096 & 0.64 & -4.26 & 35 & $\leq .001 * *$ & 1.44 \\
\hline Participating in extracurricular events (sports, clubs) & -4.78 & 29 & $\leq .001 * *$ & 1.78 & -3.33 & 34 & $.002 *$ & 1.15 \\
\hline Making professors respect you & -3.00 & 29 & $.005^{*}$ & 1.12 & -1.04 & 34 & .304 & 0.36 \\
\hline Attending class regularly & -1.68 & 29 & .103 & 0.62 & -0.32 & 35 & .744 & 0.11 \\
\hline Attending class consistently in a dull course & -2.26 & 29 & $.031 *$ & 0.84 & -0.37 & 33 & .711 & 0.13 \\
\hline Make a professor think you're paying attention in class & -1.53 & 29 & .136 & 0.57 & -1.85 & 34 & .073 & 0.63 \\
\hline Understanding most ideas you read in you tests & -0.89 & 29 & .380 & 0.33 & -4.06 & 35 & $\leq .001 * *$ & 1.38 \\
\hline Understanding most ideas presented in class & -1.48 & 29 & .147 & 0.55 & -4.54 & 34 & $\leq .001 * *$ & 1.56 \\
\hline Performing simple math computations & -1.07 & 29 & .293 & 0.40 & -1.55 & 35 & .130 & 0.52 \\
\hline Using a computer & 1.64 & 29 & .110 & -0.61 & -1.35 & 35 & .183 & 0.46 \\
\hline Mastering most content in a math course & 0.00 & 29 & 1.000 & 0.00 & -3.24 & 35 & $.003^{*}$ & 1.10 \\
\hline Talking to a professor privately to get to know him or her & -3.39 & 29 & $.002 *$ & 1.26 & -5.36 & 35 & $\leq .001 * *$ & 1.81 \\
\hline Relating course content to materials in other courses & -2.85 & 28 & $.008 *$ & 1.08 & -4.58 & 34 & $\leq .001 * *$ & 1.57 \\
\hline Challenging a professor's opinion in class & -4.03 & 29 & $\leq .001 * *$ & 1.50 & -2.26 & 35 & $.030 *$ & 0.76 \\
\hline Applying lecture content to a laboratory session & -5.44 & 29 & $\leq .001 * *$ & 2.02 & -2.16 & 35 & $.038 *$ & 0.73 \\
\hline
\end{tabular}


Making good use of the library

Getting good grades

Spreading out studying instead of cramming

Understanding difficult passages in textbooks

Mastering content in a course you're not interested in

$\begin{array}{llllllll}-6.96 & 29 & \leq .001 * * & 2.59 & -5.08 & 35 & \leq .001 * * & 1.72 \\ -0.23 & 29 & .813 & 0.09 & -3.20 & 35 & .003 * & 1.08 \\ -4.82 & 29 & \leq .001 * * & 1.79 & -4.22 & 35 & \leq .001 * * & 1.43 \\ -5.41 & 29 & \leq .001 * * & 2.01 & -3.95 & 35 & \leq .001 * * & 1.34 \\ -4.17 & 29 & \leq .001 * * & 1.55 & -1.50 & 34 & .142 & 0.52\end{array}$

*Paired t-test, two-tail $p \leq .05$

$* *$ Paired t-test, two-tail $p \leq .01$

\section{Mean Gain Score Comparison}

Through examination of the mean pretest scores of treatment groups' responses to the CASES and CSEI an initial difference in baseline scores was uncovered (Table 5, 7). In order to better examine the influence of treatments, mean gain score comparisons (independent sample t-tests, two-tail, $\alpha=.05$ ) for both CASES and CSEI scales were evaluated (Tables 6 and 8 ).

Table 5 presents the pre-test and post-test means scores for each College Self-Efficacy scale and for each treatment group ('Non-integrated' and 'Integrated'). The mean gain score (post-test - pre-test) are also presented. All mean gain scores are positive and indicate that post-test scores are higher than pre-test scores for both 'Non-Integrated' and 'Integrated' study participants, indicating an overall increase among participants' perceived self-efficacy.

Table 6 presents comparisons between mean differences for 'Non-Integrated' and 'Integrated' study groups (independent sample t-test, 2-tailed, $\alpha=.05$ ). When College SelfEfficacy scales were examined, there were no significant differences identified. This result highlights that response from both treatment groups increased in a similar manner between pre-test and post-test responses (Table 6).

Table 7 presents the pre-test and post-test means scores for the College Academic SelfEfficacy Scales. Like the College Self Efficacy Inventory responses, these scores were generally 
positive for both 'Non-integrated' and 'Integrated' groups, with one exception (i.e., 'Using a computer') - this was also noted earlier in this chapter.

Table 8 presents the comparisons between mean differences for 'Non-integrated' and 'Integrated' groups (independent sample t-test, 2-tailed, $\alpha=.05$ ). 'Non-integrated' respondents' mean gain score were significantly higher than 'Integrated' participants when examining one of the 33 College Academic Self-Efficacy Scales, 'Applying lecture content to a laboratory session' $(\mathrm{p}=.034)$. 'Integrated' study participants' mean gain scores were significantly higher when the following scales were examined: 'Running for student government office' $(p=.010)$, 'Using a computer' ( $p=.043)$, and 'Mastering most content in a math course' $(p=.034)$. More positive and significant effects were measured in the 'Integrated' group. 
Table 5 Pre, post test and mean gain score responses to College Self-Efficacy Inventory by treatment group

\begin{tabular}{|c|c|c|c|c|c|c|}
\hline \multirow[b]{2}{*}{ College Self-Efficacy Inventory } & \multicolumn{3}{|c|}{ 'Non-integrated' } & \multicolumn{3}{|c|}{ 'Integrated' } \\
\hline & $\begin{array}{l}\text { Pre-test } \\
\text { Mean }\end{array}$ & $\begin{array}{l}\text { Post- } \\
\text { test } \\
\text { Mean } \\
\end{array}$ & $\begin{array}{l}\text { Mean } \\
\text { Gain } \\
\text { score }\end{array}$ & $\begin{array}{l}\text { Pre-test } \\
\text { Mean }\end{array}$ & $\begin{array}{l}\text { Post- } \\
\text { test } \\
\text { Mean }\end{array}$ & $\begin{array}{l}\text { Mean } \\
\text { Gain } \\
\text { Score }\end{array}$ \\
\hline \multicolumn{7}{|l|}{ Social Self Efficacy } \\
\hline Make new friends at college & 7.83 & 8.53 & 0.70 & 8.10 & 8.64 & 0.54 \\
\hline Talk to your professor/instructor & 6.80 & 7.93 & 1.13 & 7.24 & 8.05 & 0.81 \\
\hline $\begin{array}{l}\text { Ask a professor or instructor a question outside } \\
\text { of class }\end{array}$ & 7.03 & 8.00 & 0.97 & 7.16 & 8.11 & 0.95 \\
\hline Do well on your exams & 6.53 & 7.30 & 0.77 & 6.72 & 7.54 & 0.82 \\
\hline Talk with a school academic and support staff & 6.48 & 7.82 & 1.34 & 6.89 & 7.91 & 1.02 \\
\hline Ask a question in class & 6.70 & 7.83 & 1.13 & 6.86 & 7.72 & 0.86 \\
\hline Participate in class discussions & 7.03 & 7.86 & 0.83 & 7.13 & 7.97 & 0.84 \\
\hline Get a date when you want one & 6.58 & 7.72 & 1.14 & 7.25 & 8.00 & 0.75 \\
\hline Join a student organization & 6.60 & 8.10 & 1.50 & 7.08 & 8.08 & 1.00 \\
\hline \multicolumn{7}{|l|}{ Course Self-Efficacy } \\
\hline Take good class notes & 6.46 & 7.46 & 1.00 & 6.72 & 7.45 & 0.73 \\
\hline Research a term paper & 6.31 & 7.13 & 0.82 & 6.97 & 7.62 & 0.65 \\
\hline Understand your textbook & 6.13 & 7.10 & 0.97 & 6.54 & 7.32 & 0.78 \\
\hline Write a course paper & 6.66 & 7.03 & 0.37 & 7.37 & 7.72 & 0.35 \\
\hline Manage your time effectively & 6.10 & 7.66 & 1.56 & 6.86 & 8.00 & 1.14 \\
\hline Keep up to date with your school work & 7.20 & 7.83 & 0.63 & 7.75 & 8.02 & 0.27 \\
\hline \multicolumn{7}{|l|}{ Roommate Self-Efficacy } \\
\hline Divide chores with others you live with & 6.93 & 7.65 & 0.72 & 6.94 & 7.89 & 0.95 \\
\hline Get along with other you live with & 7.55 & 8.44 & 0.89 & 7.75 & 8.13 & 0.38 \\
\hline Socialize with others you live with & 8.00 & 8.40 & 0.40 & 8.29 & 8.62 & 0.33 \\
\hline Divide space in your residence (if applicable) & 6.92 & 8.20 & 1.28 & 7.41 & 8.20 & 0.79 \\
\hline
\end{tabular}


Table 6 Comparison between treatment group mean gain score on the College Self-

\begin{tabular}{|c|c|c|c|c|}
\hline College Self-Efficacy Inventory & $\mathbf{t}$ & df & $\begin{array}{l}\text { Sig. (2- } \\
\text { tailed) }\end{array}$ & $\begin{array}{c}\text { Mean } \\
\text { Difference }\end{array}$ \\
\hline \multicolumn{5}{|l|}{ Social Self-Efficacy } \\
\hline Make new friends at college & 0.75 & 65 & .450 & .159 \\
\hline Talk to your professor/instructor & 1.19 & 65 & .238 & .322 \\
\hline $\begin{array}{l}\text { Ask a professor or instructor a question outside of } \\
\text { class }\end{array}$ & 0.06 & 64 & .948 & .022 \\
\hline Do well on your exams & -0.18 & 65 & .858 & -.044 \\
\hline Talk with a school academic and support staff & 0.86 & 64 & .389 & .317 \\
\hline Ask a question in class & 0.72 & 65 & .474 & .268 \\
\hline Participate in class discussions & -0.01 & 65 & .988 & -.004 \\
\hline Get a date when you want one & 1.17 & 63 & .244 & .387 \\
\hline Join a student organization & 1.27 & 48 & .210 & .500 \\
\hline \multicolumn{5}{|l|}{ Course Self-Efficacy } \\
\hline Take good class notes & 0.88 & 65 & .381 & .270 \\
\hline Research a term paper & 0.51 & 64 & 610 & .178 \\
\hline Understand your textbook & 0.60 & 65 & .545 & .182 \\
\hline Write a course paper & 0.04 & 65 & .965 & .015 \\
\hline Manage your time effectively & 1.11 & 65 & .270 & .431 \\
\hline Keep up to date with your school work & 1.31 & 65 & .194 & .363 \\
\hline \multicolumn{5}{|l|}{ Roommate Self-Efficacy } \\
\hline Divide chores with others you live with & -0.70 & 64 & .485 & -.221 \\
\hline Get along with others you live with & 1.67 & 64 & .099 & .518 \\
\hline Socialize with others you live with & 0.25 & 65 & .798 & .075 \\
\hline Divide space in your residence (if applicable) & 1.47 & 57 & .145 & .485 \\
\hline
\end{tabular}

*Independent t-test, two-tail $\mathbf{p} \leq .05$ 
Table 7 Pre, post test and mean gain score responses to Academic Self-Efficacy Survey by treatment group

\begin{tabular}{|c|c|c|c|c|c|c|}
\hline \multirow[b]{2}{*}{ Academic Self-Efficacy Survey } & \multicolumn{2}{|c|}{ Non 'Integrated' } & \multirow[b]{2}{*}{$\begin{array}{c}\text { Mean } \\
\text { Gain } \\
\text { Score }\end{array}$} & \multicolumn{3}{|c|}{ 'Integrated' } \\
\hline & $\begin{array}{l}\text { Pre-test } \\
\text { Mean }\end{array}$ & $\begin{array}{c}\text { Post- } \\
\text { test } \\
\text { Mean }\end{array}$ & & $\begin{array}{l}\text { Pre-test } \\
\text { Mean }\end{array}$ & $\begin{array}{l}\text { Post- } \\
\text { test } \\
\text { Mean }\end{array}$ & $\begin{array}{c}\text { Mean } \\
\text { Gain } \\
\text { Score }\end{array}$ \\
\hline Taking well-organized notes during a lecture & 3.77 & 4.00 & 0.23 & 3.76 & 4.27 & 0.51 \\
\hline Participating in class a discussion & 3.67 & 4.23 & 0.56 & 3.70 & 4.32 & 0.62 \\
\hline Answering a question in a large class & 3.23 & 4.03 & 0.80 & 3.46 & 4.00 & 0.54 \\
\hline Answering a question in a small class & 4.37 & 4.63 & 0.26 & 4.27 & 4.78 & 0.51 \\
\hline $\begin{array}{l}\text { Taking "objective" tests (multiple-choice, T-F, } \\
\text { matching) }\end{array}$ & 4.07 & 4.30 & 0.23 & 4.05 & 4.38 & 0.33 \\
\hline Taking essay tests & 3.43 & 3.57 & 0.14 & 3.49 & 3.84 & 0.35 \\
\hline Writing a high quality term paper & 3.37 & 3.60 & 0.23 & 3.30 & 3.86 & 0.56 \\
\hline Listen carefully during a lecture on a difficult topic & 3.70 & 3.93 & 0.23 & 3.73 & 4.22 & 0.49 \\
\hline Tutoring another student & 3.14 & 3.62 & 0.48 & 2.84 & 3.51 & 0.67 \\
\hline Explaining a concept to another student & 3.83 & 4.13 & 0.30 & 3.61 & 4.11 & 0.50 \\
\hline $\begin{array}{l}\text { Asking a professor in class to review a concept you } \\
\text { don't understand }\end{array}$ & 3.50 & 4.33 & 0.83 & 3.47 & 4.08 & 0.61 \\
\hline Earning good marks in most courses & 3.90 & 4.21 & 0.31 & 4.06 & 4.28 & 0.22 \\
\hline Studying enough to understand content thoroughly & 3.57 & 4.13 & 0.56 & 3.94 & 4.28 & 0.34 \\
\hline Running for student government office & 2.23 & 2.40 & 0.17 & 2.17 & 2.81 & 0.64 \\
\hline Participating in extracurricular events (sports, clubs) & 4.10 & 4.60 & 0.50 & 4.00 & 4.63 & 0.63 \\
\hline Making professors respect you & 4.23 & 4.60 & 0.37 & 4.23 & 4.37 & 0.14 \\
\hline Attending class regularly & 4.70 & 4.83 & 0.13 & 4.75 & 4.78 & 0.03 \\
\hline Attending class consistently in a dull course & 4.57 & 4.77 & 0.20 & 4.50 & 4.56 & 0.06 \\
\hline $\begin{array}{l}\text { Make a professor think you're paying attention in } \\
\text { class }\end{array}$ & 4.47 & 4.67 & 0.20 & 4.40 & 4.63 & 0.23 \\
\hline Understanding most ideas you read in you tests & 4.03 & 4.17 & 0.14 & 3.86 & 4.33 & 0.47 \\
\hline Understanding most ideas presented in class & 4.00 & 4.23 & 0.23 & 4.06 & 4.49 & 0.43 \\
\hline Performing simple math computations & 4.07 & 4.20 & 0.13 & 4.22 & 4.47 & 0.25 \\
\hline Using a computer & 4.77 & 4.57 & -0.20 & 4.78 & 4.86 & 0.08 \\
\hline Mastering most content in a math course & 3.90 & 3.90 & 0.00 & 4.00 & 4.42 & 0.42 \\
\hline $\begin{array}{l}\text { Talking to a professor privately to get to know him } \\
\text { or her }\end{array}$ & 3.80 & 4.33 & 0.53 & 3.47 & 4.39 & 0.92 \\
\hline $\begin{array}{l}\text { Relating course content to materials in other } \\
\text { courses }\end{array}$ & 3.59 & 4.07 & 0.48 & 3.74 & 4.34 & 0.60 \\
\hline Challenging a professor's opinion in class & 2.73 & 3.33 & 0.60 & 2.97 & 3.39 & 0.42 \\
\hline Applying lecture content to a laboratory session & 3.13 & 3.93 & 0.80 & 3.78 & 4.11 & 0.33 \\
\hline Making good use of the library & 3.70 & 4.50 & 0.87 & 3.81 & 4.61 & 0.80 \\
\hline Getting good grades & 4.27 & 4.30 & 0.03 & 4.22 & 4.61 & 0.39 \\
\hline Spreading out studying instead of cramming & 3.23 & 4.20 & 0.97 & 3.42 & 4.25 & 0.83 \\
\hline Understanding difficult passages in textbooks & 3.07 & 4.00 & 0.93 & 3.42 & 3.97 & 0.55 \\
\hline $\begin{array}{l}\text { Mastering content in a course you're not interested } \\
\text { in }\end{array}$ & 3.07 & 3.93 & 0.86 & 3.46 & 3.80 & 0.34 \\
\hline
\end{tabular}


Table 8 Comparison between treatment group mean gain score on the Academic Self-Efficacy Survey

Mean

College Academic Self-Efficacy Scale

Sig. (2- Differenc

\begin{tabular}{|c|c|c|c|c|}
\hline & $\mathbf{t}$ & df & tailed) & e \\
\hline Taking well-organized notes during a lecture & -1.40 & 65 & .164 & -0.280 \\
\hline Participating in class a discussion & -.266 & 65 & .791 & -0.055 \\
\hline Answering a question in a large class & 1.04 & 65 & .298 & 0.259 \\
\hline Answering a question in a small class & -1.40 & 65 & .164 & -0.247 \\
\hline Taking "objective" tests (multiple-choice, T-F, matching) & -0.48 & 65 & .627 & -0.091 \\
\hline Taking essay tests & -1.40 & 65 & .165 & -0.218 \\
\hline Writing a high quality term paper & -1.76 & 65 & .082 & -0.334 \\
\hline Listen carefully during a lecture on a difficult topic & -1.30 & 65 & .197 & -0.253 \\
\hline Tutoring another student & -0.94 & 64 & .348 & -0.193 \\
\hline Explaining a concept to another student & -0.92 & 64 & .360 & -0.200 \\
\hline $\begin{array}{l}\text { Asking a professor in class to review a concept you don't } \\
\text { understand }\end{array}$ & 0.97 & 64 & .335 & 0.222 \\
\hline Earning good marks in most courses & 0.46 & 63 & .644 & 0.088 \\
\hline Studying enough to understand content thoroughly & 1.05 & 64 & .296 & 0.233 \\
\hline Running for student government office & -2.64 & 58 & $.010 *$ & -0.472 \\
\hline Participating in extracurricular events (sports, clubs) & -0.59 & 52 & .553 & -0.129 \\
\hline Making professors respect you & 1.20 & 63 & .234 & 0.224 \\
\hline Attending class regularly & 0.89 & 64 & .372 & 0.106 \\
\hline Attending class consistently in a dull course & 0.75 & 62 & .454 & 0.141 \\
\hline Make a professor think you're paying attention in class & -0.15 & 63 & .874 & -0.029 \\
\hline Understanding most ideas you read in you tests & -1.81 & 64 & .074 & -0.339 \\
\hline Understanding most ideas presented in class & -1.10 & 63 & .275 & -0.195 \\
\hline Performing simple math computations & -0.55 & 64 & .581 & -0.117 \\
\hline Using a computer & -2.08 & 43 & $.043^{*}$ & -0.283 \\
\hline Mastering most content in a math course & -2.16 & 64 & $.034^{*}$ & -0.417 \\
\hline Talking to a professor privately to get to know him or her & -1.62 & 64 & .109 & -0.383 \\
\hline Relating course content to materials in other courses & -0.55 & 62 & .580 & -0.117 \\
\hline Challenging a professor's opinion in class & 0.75 & 64 & .454 & 0.183 \\
\hline Applying lecture content to a laboratory session & 2.16 & 64 & $.034^{*}$ & 0.467 \\
\hline Making good use of the library & 0.29 & 64 & .769 & 0.061 \\
\hline Getting good grades & -1.93 & 64 & .058 & -0.356 \\
\hline Spreading out studying instead of cramming & 0.47 & 64 & .639 & 0.133 \\
\hline Understanding difficult passages in textbooks & 1.71 & 64 & .091 & 0.378 \\
\hline Mastering content in a course you're not interested in & 1.67 & 63 & .099 & 0.524 \\
\hline
\end{tabular}

*Independent t-test, two-tail p $\leq .05$ 


\section{Discussion and Conclusion}

The purpose of this chapter is to revise, summarize and discuss the research findings. Additional to the discussion of the findings, suggestions and implications for practitioners, program developers and directors will be covered. Furthermore suggestions will be made to improve future research and to recommend new areas of concentration for future studies.

The purpose of this quasi experimental study has three areas of focus: (1) to examine the effects of a challenge course-based orientation program (CCBOP) on participants' anticipated academic and college self-efficacy, (2) to examine the different effects of two styles of facilitation on CCBOP participants anticipated academic and college self-efficacy and (3) to determine any influence of demographic factors on CCBOP participants' anticipated academic and college self-efficacy. These areas will be discussed in this chapter.

\section{Research question \#1}

Does a university's challenge course-based pre-orientation program elicit changes in participants' perceived academic self-efficacy and/or perceived college self-efficacy?

\section{CSEI}

Two individual scales were used to measure change in self-efficacy generally associated with student involvement in the CCBOP, the College Academic Self-Efficacy Scale (CASES) and the College Self-Efficacy Inventory (CSEI). A pair wise t-test was used to examine the change between CSEI pre-test and post-test responses, and the results indicate that all participants perceived a positive change in all 19 measures that were included in the study instrument. This indicates that the program, which includes the University 101 curriculum and use of a challenge 
course with varying levels of facilitation, is effective in increasing participants perceived college focused self-efficacy. Measures with the highest increase in students confidence were 'Talk with a school academic and support staff' (MD =-1.16), 'Manage your time effectively' (MD = $-1.3)$, 'Join a student organization' ( $M D=-1.22)$, 'Ask a question in class' $(M D=-.98)$, and 'Divide space in your residence (if applicable)' (MD $=-1.00)$. These increases can be linked to several of the discussions outlined in the 'Leave-a-trace' curriculum. Students are engaged in a discussion led by upperclassmen concerning programs, resources and organizations that are available to them. This discussion includes specific organization as well as specific support staff members. The program's emphasis on presenting this information to first year students as well as offering personal connections (verbal persuasion) influenced participants' efficacy expectation. Student's confidence to divide their space most likely is generalized from their vicarious experience throughout the duration of the program. The students' ability to survive within the limited space of the tents shared among participants and having to be responsible for their own belongings perhaps produced confidence generalizable to their upcoming situation of sharing space within their dorm.

Students' increase in reported self-efficacy, 'Ability to manage their time effectively', can be partially attributed to the CCBOP experience. Activities presented to the students included a general necessity to manage their time in order to complete the task. This provided a vicarious experience opportunity, even though was not directly analogous to upcoming college experiences, that students were able to generalize their confidence into the new domain. Along the same lines, although not directly related, students were able to increase in perceived confidence when faced with asking questions in class. Providing individual input and 
asking question during class discussions is stressed by the facilitators during their first college course. As the course instructors they strive to develop mutual respect and understanding which provides an atmosphere of comfort during the class discussions. This ability to ask questions in a safe and supportive arena most likely eased concerns of not knowing the answers. Students realized that many of their classmates may have the same questions in mind. From this interaction students felt more confident in translating this new understanding into the more traditional classrooms.

Responses to the CSEl pre-test, post-test comparison by treatment group, as mentioned in the 'Results' chapter produced effect sizes which closely mimicked the results of the test for significance. 'Large' effects (1.31. - 1.74) were reported when all participants' pre-test, posttest responses to the eight items of the Social Self-Efficacy sub-scale were examined. This reiterates the findings of previous research promoting the relationship between wilderness orientation programs and social support (Bell, 2006; Gass, 1984). All other items except for two items of the Course Self-Efficacy and one in the Roommate Self-Efficacy saw a 'large' effect size. The 'medium' effect of the three items ('Write a course paper', $d=0.52$, 'Socialize with others you live with', $d=0.61$, 'Keep up to date with your school work', $d=0.77$ ) indicated that although the CCBOP is effective in increasing students' self-efficacy perception no all aspects of the academic and roommate type tasks were as influenced as others.

\section{CASES}

The College Academic Self-Efficacy Scale is the second instrument used to gauge any change in students' perceived self-efficacy. The CASES when compared to the CSEI has exclusive and perhaps more in depth focus on academics. Responses to four CASES post-test 
items did not improve significantly from the pre-test (see Table 2). Those scale items include: 'Attending class regularly' ( $p=.199)$, 'Attending class consistently in a dull course' $(p=.185)$, 'Performing simple math computations' $(p=.063)$, 'Using a computer' $(p=.495)$.

For example, confidence in 'Attending class regularly' received the second highest pretest response ( $\bar{x}=4.73$ on a 5.00 scale). With such a high pre-test score, there is little room for improvement in the post-test. Although it was not significant, respondents did report an increase of 0.07 to post test sample mean of $\bar{x}=4.80$. A larger sample of participants (more power in the analysis) may be necessary when pre-test scores are high.

Two other examples of CASES scale items that did not receive significantly higher posttest responses include 'Using a computer' (pre-test mean of $\bar{x}=4.77$, post-test mean $\bar{x}=4.73$ ) and 'Performing simple math computations' (pre test mean $\bar{x}=4.15$, post test mean $\bar{x}=4.35$ ). Students' confidence in 'Using a computer' received the highest response among all the items on the CASES. This high pre-test level is not surprising considering the young age of the respondents (assuming they were exposed to technology throughout their childhood). In addition, the curriculum did not specifically deal with computer use or skills. That is, with no direct focus on computer use, the lack of influence on self-efficacy was not surprising. Several of the items that produced the largest mean differences between pre test and post test response were concerned with students confidence in the following: 'Asking a professor in class to review a concept you don't understand' (MD = -.712), 'Talking to a professor privately to get to know him or her' (MD = -.742), 'Making good use of the library' (MD = -.833), 'Spreading out studying instead of cramming' (MD = -.894), and 'Understanding difficult passages in textbooks' $(M D=-.727)$. Not surprisingly these same items were associated with 'large' effect sizes (see 
Table 2) supporting the significant differences that were identified. In total a 'large' effect size was produced for 23 items responses. All of the remaining item responses except for one, even though not all are statistically significant, produced 'small' to 'medium' effects. Responses to the lone item, 'Using a computer' produced a d value equal to 0.17 ( $p>.05$ ) equating to only a slight gain from pre-test to post-test examination. This is not surprising due to the intentional removal of technology available during the experience, as well as curriculum about the use of technology.

\section{Summary of Research, Question \#1}

The evaluation of CCBOP indicates it is effective in increasing students' perceived selfefficacy in both college and academic self-efficacy domains based upon pre-test and post-test comparison. Responses to 29 of the 33 CASES items were significantly higher in the post-testthese items were highly generalizable from the program design. The four remaining items were concerned with situations dealing with specific skills and were less generalizable from the challenge course experience. The effect size reiterated the importance of the significance found among the 29 items, all of which were of 'large' and 'medium' effect.

Responses to the 19 CSEI item measures were significantly higher in the post-test regardless of the treatment program. The effect size being all 'large' and 'medium' and the responses difference significant, this indicates that the CCBOP had positive effects on the perceived self-efficacy of the first year students who participated in the study. It is important to note the overwhelming positive results of the Social Self-Efficacy subscale. The remaining subscales as well as the CASES had a high majority of items with statistical significance and effect size; however, not all domains were as impacted by ССВOP experience as others. 
Students' self-efficacy perception in areas such as mathematics or, certainty of getting good grades was not as influential to the increase than other items such as 'Making good use of the library', or 'Getting to better know their professor'.

\section{Research Question \#2}

Does a higher level of curriculum integration of the challenge course based preorientation program elicit any change in participants' perceived academic self-efficacy and/or college self-efficacy?

In order to examine any difference between the treatment groups, paired t-tests were conducted between pre and post-test responses. In addition to the paired t-tests, independent t-tests of the mean gain scores of each treatment group were conducted to compare the effect of 'Integrated' and 'Non-integrated' programs.

\section{CSEI}

The paired t-test examination of responses for both treatment groups on all 19 items produced statistically significant differences. Several differences between the treatments groups' responses were found once broken down by treatment groups as well as subscales. As suspected from the literature (i.e. Bell, 2006; Gass, 1984) participants' self-efficacy expectancy increased in the Social Self-Efficacy subscale reiterating the effect of pre orientation programs influence on social confidence. Both treatment groups on two individual items 'Socialize with others you live with' from the Roommate Self-Efficacy subscale and 'Write a course paper' from the Course Self-Efficacy subscale failed to produce significant difference. Speculations as to why participants did not increase in confidence in their ability to complete the latter task are twofold. The University 101 course curriculum presented to both treatment groups does not 
specifically address skills or techniques necessary to writing a term paper. With a high average pre-test score among both treatment groups ('Non-integrated' mean $=6.66$, 'Integrated' mean $=7.3$ ), and without any specific instruction the participants anticipated self-efficacy was not affected by a generalized college focus. This however contradicts the result of the CASES paired t-test results which indicated that the 'Integrated' group strengthened their belief in being able to "Write high quality term paper" ( $p<.001)$. Perhaps there was confusion created by the wording used that influenced their responses. Difference between the points of the Likert-type scale could have covered or uncovered a subtle difference. Another factor may come from the mindset of the participants. A sizeable portion of students' apprehension is focused on the social acceptance and integration. With the course conducted prior to the semester and occurring in groups of other incoming freshman and making strides in their socialization takes precedence over what can seem as the far off concern of academic expectations.

Conversely, confidence that they would be able to 'Socialize with others they live with' tends to be more generalizeable from their experience living along side strangers for the duration of the experience. Students did not significantly increase in their confidence in their ability to complete this task. Pre-test scores of 'Non-integrated' and 'Integrated' test groups are 8.00 and 8.29 on a 9 point scale and the post-test increased by 0.40 and 0.33 respectively. Although the level of increase was not significant, the pre-test scores are the highest of all item responses. The post-test scores proved to be the second highest among responses showing that students are entering the program at high level of confidence in their abilities. The higher the initial response is the more difficult it is to create an improvement. In essence, a saturation 
point is reached; however, the lower the level of self-efficacy the more room available and a higher likelihood of an increase.

\section{CASES}

Of the 4 items that were deemed insignificant in the CASES paired t-test among all treatment groups, when examined by each individual treatment, 3 remained insignificant ('Attending class regularly' ('Non-integrated' p=.103, 'Integrated' p=.744), 'Performing simple math computations' ('Non-integrated' $p=.293$, 'Integrated' $p=.130$ ), 'Using a computer' ('Nonintegrated' $p=.110$, 'Integrated' $p=.183$ )). The remaining statement ('Attending class consistently in a dull course') when examined by individual treatment groups proved to be significant only among the 'Non-integrated' treatment ( $p=.031)$. Behind 'Using a computer' and 'Attending class regularly', 'Attending class consistently on dull course' has the highest pre-test score. One possible reason that the 'Non-integrated' treatment group improved is that the participants found the program to be less enjoyable and were able to generalize their ability to pay attention, to attending a dull course. That particular item along with 'Mastering content in a course you're not interested in' ('Non-integrated', $p \leq .001, d=1.55$, 'Integrated', $p=.142, d=$ 0.52 ) indicates that the 'Integrated' group was more likely to development some form of coping skill.

On the other hand 14 items remained significant among each individual treatment group that was significant in the initial paired t-test. Of those 14 items five maintained a pvalue equal to or less than .001 among both treatment groups ('Asking a professor in class to review a concept you don't understand', 'Participating in a class discussion', 'Making good use 
of the library', 'Spreading out studying instead of cramming', 'Understanding difficult passages in textbooks'). The underlying themes of several of these items are indirectly experienced while involved in the CCBOP and easily are generalized into the greater context. For example students participate in group discussions that on face value are starkly different from what is anticipated in on campus courses; however the experience of providing individual input is easily gerneralized to traditional class discussions. Although it is not the exact setting or topic as other traditional classes the discussions experienced during the CCBOP have a high similarity in personal experience. Several other items also deal with resources and their use by participants. Facilitators stress the importance of being aware of programs and resources that are available to students not only in one specific class but throughout group discussions. The casual atmosphere of the class discussions more than likely allowed the students to realize that they are not the only ones that have questions and fight through the discomfort of asking questions and sharing their opinion with peers and instructors.

Responses to 11 individual items by the 'Integrated' treatment group were significantly different between pre and post-tests, whereas responses provided by the 'Non-integrated' did not differ significantly (see Table 4). Significant differences were identified for the following items: 'Understanding most ideas you read in you test', 'Understanding most ideas presented in class', 'Mastering most content in a math course', 'Getting good grades', 'Taking objective tests (multiple-choice, T-F, matching)', 'Taking essay tests', 'Writing a high quality term paper', 'Listen carefully during a lecture on a difficult topic', 'Taking well-organized notes during a lecture', 'Explaining a concept to another student', and 'Running for student government office'. With such a high number of pre and post-test measures that differed significantly in the 
'Integrated' treatment group, it seems that most of the CCBOP participants were better able to generalize and apply their experiences to their upcoming transition into college. The 'Integrated' treatment group was able make a greater connection from experiences on the challenge course to the skill specific academic tasks through the guided exploration of the activities. Surprisingly, students reported the greatest change on self-efficacy expectation, wherein the tasks statements indicate attainment of very specific academic skill set (Taking objective tests (multiple-choice, T-F, matching)', 'Taking essay tests', 'Writing a high quality term paper'). The direct connection of the challenge course activity and accompanied class seems to have assisted students in feeling prepared with specialized skills necessary for academic success. As mentioned previously, all students in the CCBOP were entering the course with a high level of confidence. This indicated that the population participating are already highly confident and perhaps academically prepared individuals. Nonetheless, the study was able to measure student improvement in a multitude of areas.

Students exposed to the 'Non-integrated' treatment were not as likely to show significant improvement on the CASES. In total, significant improvement on three scale items were identified during analysis of the 'Integrated' treatment groups' responses. 'Nonintegrated" students only, showed more confidence in "Mastering content in a course you're not interested in", "Earning good marks in most courses", and "Making professors respect you". This shows that the idea of persistence and individual successful easily translated from the challenge course activities; however, the much more specific items that were covered in the separated class were less impactful. Although successful students exposed to the 'Nonintegrated' treatment were able to have a much more generalized sense of confidence, the 
'Integrated' group was better able to apply the specifics of the experience and accompanying class to their upcoming transition into college life.

Unique differences were found when examining the effect size of CASES responses. The majority of effect sizes were concurrent with the results of the significance tests with the 'Integrated' treatment group producing a higher level of gain. Examples which have already been highlighted by $p$-values are items such as 'Taking essay tests' ('Integrated', d=1.13, 'Nonintegrated', d= 0.43), 'Writing a high quality term paper' ('Integrated', d=1.50, 'Non-integrated', $d=0.61$ ), and 'Understanding most ideas you read in your tests' ('Integrated', $d=1.38$, 'Nonintegrated', $d=0.33$ ). Interestingly enough more extreme differences in effect size between treatment group is seen in three individual statements. Students exposed to the 'Nonintegrated' treatment produced a score of almost no effect pertaining to 'Getting good grades' $(d=0.09)$, were as the 'Integrated' group produced a 'large' effect size. Responses by the 'Nonintegrated' group to the next two statements 'Mastering most content in a math course' and 'Using a computer' produced no effect and even negative effect respectively $(d=0.00, d=-0.610)$ were as the 'Integrated' group' were of a 'large' and 'small' effect (respectively $d=1.10, d=$ 0.46).

The final two statements were not specific skills or lessons of the CCBOP curriculum which created a lack of expectation in any changes. Perhaps the increase seen with in the 'Integrated' treatment can be draw, as previously mentioned, from the generalizability of generic academic success tips and skills. The response to 'Getting good grades' was starkly different from anticipated. Increase among 'Integrated' treatment group individuals response can be attributed to the holistic integration of the academic curriculum. 


\section{Summary of Research Question \#2}

Review of the paired t-test results by treatment group shows that those students who were presented with the curriculum integration while participating in the CCBOP were likely to respond with greater sense of confidence in successfully accomplishing academic tasks. Tasks which proved to have a significant difference among the 'Integrated' treatment group for the most part required a specific skill set. The 'Non-integrated' treatment group proved that they gained confidence in general tasks.

The social portion of the CSEI, Social Self-Efficacy subscale, not surprisingly produced significance among both the 'Integrated' and 'Non-integrated' group. This is indicative to previous research. The social elements of meeting with peers prior to the beginning of the semester and sharing a unique common experience can increase students' belief they can be socially successful in later situations.

The responses produced by the Roommate Self-Efficacy subscale indicated that both treatment groups were able to increase in confidence in most areas of having to cope with living with others. Of the items whose paired t-test results produced no significant difference, their pre-test scores were the highest of all other statements. This indicates that for the most part participants are entering into the program with an already high self-efficacy belief in their social abilities. Response comparison of the academic portion of the CSEI, the Course SelfEfficacy subscale, produced for the majority results in line with the CASES. One surprising result indicates a contradiction in the result of the CASES. 'Integrated' treatment group members increased in their self-efficacy beliefs in 'Writing a high quality term paper' on the CASES; however, no such change was found with the statement, "Write a course paper". This brings 
uncertainty to whether they were asking the same question. If so concerns of the validity of either scale are brought to light.

CASES results were divided throughout the scale by the treatment group. The 'Nonintegrated' group was more apt to increase in their self-efficacy perception with tasks that could be considered coping skills ('Attending class in a dull course', 'Master content in a course you're not interested in'). 'Integrated' treatment participant on the other had were more likely to increase in confidence on items dealing with academic specific skills ('Taking well-organized notes during a lecture', 'Taking essay tests', 'Writing a high quality term paper'). However, overall both treatment groups were able to increase in the majority of other areas test by the scale ('Challenging a professor's opinion in class', 'Studying enough to understand content thoroughly', 'Asking a professor in class to review a concept you don't understand', 'Participating in a class discussion' and 'Answering a question in a large class').

\section{Research Question \#3}

The demographic break down of participants provided information about the homogeneity of the CCBOP participants. Age and gender break down were not surprising due the targeted population (incoming freshman with an equal number of males and females in each group). Ethnicity, although not a fair representation of the overall University population, was consistent with previous programs demographics. Lastly the home state of the students indicated a smaller percentage of instate students than the great university population; however, was still the individual majority. Perhaps the students who were instate felt that they were already confident in their transition due to the proximity of home and school. At the 
same time, out-of-state students traveling the greatest distances could not find the time to travel twice to the University, although students in states neighboring West Virginia were more open to participating in the orientation program.

\section{Research Question \#4}

From the collective view of participants' demographic responses it is fair to say that the sample population is extremely homogenous. Upon categorical examination of responses, the number of participants to identify themselves as something other than Caucasian and 18 years of age was too low to produce any valid results. Conversely division of responses based upon gender was split near perfectly. An Independent T-test of all respondents as well as treatment groups produced no significant difference among male and females responses. Males respond just the same as females when exposed to either treatment. This indicates that no gender is more inclined to respond to the treatment than the other. Lastly students from who claim West Virginia as their homes state responded no differently than those from adjacent states and others. This particular result indicates that no matter the students' relationship to the state that houses the university they are equally likely to improve in their confidence to transition into college life.

\section{CCBOP Director Considerations}

As stated in the limitation portion of this research the results of this study can only be generalized to highly similar programs only. Specific recommendation to the examined programs may also be implemented in similar programs only to be systematically explored in order to validate their implementation. The overall response and significant increases in both CASES and CSEI, indicates that the overall design of the program is capable of addressing and 
providing self-efficacy information. This most likely is accomplished through performance achievement experienced through the individual challenge course activities and their connection to the greater world. Focused on implementing key things such skill sets of planning, organizing, communicating, managing time, dealing with others and pushing beyond ones limits, these individual activities provided to be novel, memorable and reinforcing of participants effort and skills. At the same time interacting with successful upperclassmen provide a vivid example of someone they can relate to and who has been successfully able to transition into college life. This unique form of verbal persuasion occurs through the peer leaders' eagerness to provide advice as well as personal antidotes of struggle and success.

On evaluation of the treatment groups individually, the success of the 'Integrated' group students to gain a greater sense of confidence in potential upcoming academic challenges can be attributed to the facilitation style. A level of ambiguity remains as to at what point does a challenge course experience with a curriculum start or more importantly stop being 'Integrated'; however it seems that a general attempt to integrate curriculum and challenge course activities had proven effective. It would also be suggested that the same time that zero level of integration occurred with students eager to assimilate experiences to upcoming ones and facilitators trained to assist students in self and group discovery. One thought is that there is a certain amount of carry over, integration and non-integration from one treatment to another occurred that lead to the success of all the participants. This may also be seen due the level of vulnerability the student experience in their upcoming transition into college, thus making them more open to and desiring of connection from any life experience that would lend comfort and confidence. Perhaps the level of success experienced 
with integrating curriculum would not have been as high with a more academic subject matter and less open group.

It can be seen that challenge course activities are prime experiences for integrating a specific introspective treatment or curriculum through their application in therapeutic and counseling settings (Gillis \& Speelman 2008). In this particular CCBOP the same is true. The 'Integrated' curriculum design examined should continue to be implemented in the overall design of the program. Attempts to incorporate a level of curriculum integration into similar orientation programs offered by Adventure West Virginia should be made. Results show that challenge course based activities provided quality forms of specific and general self-efficacy expectancy influences; verbal persuasion, emotional arousal, performance accomplishments and vicarious experiences. If one such connection can be deliberately designed with a solid curriculum connection in other programs it can aid in producing students who college selfefficacy beliefs are high.

Aside from the expansion of curriculum integration into non challenge course but similarly designed programs, the further development of an academic preparation would be beneficial. This could assist in addressing the lack of gain in confidence on several items on the CASES. Providing a larger pool of tips and skills coupled with curriculum integration facilitation could possibly produce stronger and more focused self-efficacy expectancy beliefs.

\section{Future Research}

The research design was well constructed and sound in its methodology; however, future research of this domain should consider the following recommendation. In order to obtain further understanding of the effects of CCBOPs on students' perception of feeling 
prepared for college; future designs should incorporate a demographically similar control group. One such control group would be students who signed up for a program however were unable to make it on to the trip for one reason or another. This would provide additional support to the overall effectiveness of such programs. Additionally, soliciting students on a trip of similar length; however, utilizing a different daily activity would provide data helpful for flesh out components of each individual outdoor orientation program's influence on students' perceived self-efficacy.

A second recommendation for future research would be the incorporation of a followup-test. The use of a follow-up-test would lend information toward determining whether the observed increases is not attributed to post-group euphoria but in fact are due to the treatment. Furthermore this would provide evidence on ability of any gained benefit to remain for an extended period of time.

The utilization of both instruments allowed for a unique view on the students' perceived self-efficacy. The combination of the academic portion on the CSEl and the expanded academic instrument of the CASES allowed for both an overview paired with a more in depth examination. The Course Self-Efficacy sub-scale produced few items with no significance and small effect size. However, when compared to the CASES results a discrepancy is seen. The CSEl is a good instrument for an overarching view on first year students perceived self-efficacy on broad range of tasks considered vital to college success. The instrument compared to the CASES lacks sensitivity. A suggestion for any further research would be the utilization of multiple expanded instruments each individually focused on three components Tinto (1987) outlined as keys to a successful transition. The use of an expanded social self-efficacy 
instrument among others would identify area of less or even no change that may have been missed by the CSEl. Once such scale use by Bell (2006) in his research of first year students at Harvard and Princeton variations of pre-orientation type programs is the Campus-Focused Social Support Scale

Lastly, Bandura (1977) denoted self-efficacy expectation varies on three individual dimensions, magnitude, strength and generality. To adequately assess self-efficacy expectancy all three domains must be analyzed. Likert-type scales are able to examine strength and magnitude of self-efficacy perception, but not generality. The utilization of an instrument which measures all three would round out an understanding of any change in participants' selfefficacy expectation. One possibility would be the addition of a one-on-one interview postexperience to the current design. The addition of a self-efficacy expectancy instrument able to examine generality along with other suggestion would help to complement or triangulate results from the CASES and CSEI. 


\section{References}

Association of Experiential Education (2007). What is Experiential Education? Retrieved February 10, 2009, from http://www.aee.org/about/whatlsEE

Astin, A. W., Vogelgesang, L. J., Ikeda, E. K., \& Yee, J. A. (2000). How service learning affects students. Retrieved November 28, 2007, from University of California Los Angeles, Higher Education Research Institute Web site: http://www.gseis.ucla.edu/ heri/PDFs/HSLAS/HSLAS.PDF

Bacon, S. (1983). The conscious use of metaphor in Outward Bound. Denver, CO: Colorado Outward Bound School.

Bandura, A. (1977). Self-efficacy: Toward a unifying theory of behavioral change. Psychological Review, 84, 191-215.

Bandura, A. (1982). Self-efficacy: Mechanism in human agency. American Psychologist, 37(2), p. 122-147 Retrieved from PsycARTICLES database.

Bandura, A. (1994). Self-efficacy. In V. S. Ramachaudran (Ed.), Encyclopedia of human behavior (Vol. 4, pp. 71-81). New York: Academic Press. (Reprinted in H. Friedman [Ed.], Encyclopedia of mental health. San Diego: Academic Press, 1998).

Bandura, A. (1997). Self-efficacy: The exercise of control. New York: W. H. Freeman.

Bell, B. J. (2006). Wilderness orientation: Exploring the relationship between college peorientation programs and social support. Journal of Experiential Education, 29, 145167.

Bell, B. J. (2008). The Neighborhood Project: A National Census of Outdoor Orientation Programs at Four-Year Colleges in the United States. Martinsville, IN: Coalition for Education in the Outdoors Ninth Biennial Research Symposium Abstracts.

Boyle, S. (1986). The effects of a ropes course experience on locus of control and self-esteem (Doctoral dissertation, Oklahoma State University, 1985). Dissertation Abstracts International, 46(12), 4391B

Breheny, M. S. (2000). Investigating the effects of a low ropes course experience vs. classroom instruction on the problem-solving appraisal of college freshmen (Doctoral dissertation, Florida Institute of Technology, 2000). Dissertation Abstracts International, 61(05), 1738A. 
Burton, L. M. (1981). A critical analysis and review of the research on Outward Bound and related programs (Doctoral dissertation, Rutgers: The State University of New Jersey, 1981).

Coe, R. (2002). It's Effect Size Stupid: What effect size is and why it's important. Exeter, England: British Educational Research Association Annual Conference. Retrieved from http://www.cemcentre.org/Documents/CEM\%20Extra/EBE/ESguide.pdf

Coopersmith, S. (1990). SEI: Self-esteem Inventories. Palo Alto, CA: Consulting Psychologists Press, Inc.

Crosby, A. (1981). A Critical Look: The Philosophical Foundations of Experiential Education. In K. Waren, M. Sakofs, \& J. Hunt (Eds.), The Theory of Experiential Education. A Collection of Articles Addressing the Historical, Philosophical, Social, and Psychological Foundations of Experiential Education. Third Edition (3-13). Dubuque, IA: Kendal/Hunt. Retrieved from ERIC database.

Dartmouth Outing Club (n.d.) About the Program. (n.d.). Retrieved April 6, 2009, from http://www.dartmouth.edu/ doc/firstyeartrips/about/

Davis-Berman, J. \& Berman, D. (1996). Using the wilderness to facilitate adjustment to college: An update description of wilderness orientation programs. The Journal of Experiential Education, 19, 22-28.

Delivering Life Experiences for Over 60 Years. (n.d.). Retrieved January 18, 2009, from http://www.outwardbound.org/index.cfm/do/ind.about_history

Dewey, J. (1938/1997). Experience and education. Macmillan

Dougherty, M. A. (2005). The changes in life effectiveness following ropes course participation for Becoming an Outdoors-Woman (BOW) participants (Unpublished doctoral dissertation, West Virginia University, 2005).

Ewert, A. W. (1987). Outdoor adventure recreation: A trend analysis. Journal of Experiential Education, 5 (2), 56-67.

Ewert, A.W. (1987). Research in outdoor adventure: Overview and analysis. The Bradford Papers Annuals, 2, 15-28. May 2, 2008, from http://www.d.umn.edu/ kgilbert/ ened5560-1/Readings/Adventure\%20Research\%200verview\%20-\%20Ewert\%201987.pdf

Fears, G. \& Denke, M. S. (2001). Wilderness pursuit programs: An orientation paradigm. The Journal of College Orientation and Transition, 9, 5-12. Retrieved from ERIC database. 
Feltz, D. (1982). Path analysis of the casual elements in Bandura's theory of self-efficacy and an anxiety-based model of avoidance behaviour. Journal of Personality and Social Psychology, 62, 764-781.

Feltz, D. \& Mugno, D. (1983). A replication of the path analysis of the casual elements in Bandura's theory of self-efficacy and the influence of autonomic perception. Journal of Sport Psychology, 5, 263-277.

Fox, L., Zakley, J., Morris, R., \& Jundt, M. (1993). Orientation as a catalyst: Effective retention through academic and social integration. In M. L. Upcraft, R. H. Mullendore, B. O. Barefoot, \& D. S. Fidler (Eds.), Designing successful transitions: A guide for orientating students to college (pp. 49-59). Columbia, SC: National Resource Center for the Freshman Year Experience.

Galloway, S. (2000). Assessment in wilderness orientation programs: Effort to improve college student retention. Journal of Experiential Education, 23, 75-84.

Gass, M. A. (1985). Programming the Transfer of Learning in Adventure Education. In K. Waren, M. Sakofs, \& J. Hunt (Eds.), The Theory of Experiential Education. A Collection of Articles Addressing the Historical, Philosophical, Social, and Psychological Foundations of Experiential Education. Third Edition (131-142). Dubuque, IA: Kendal/Hunt. Retrieved from ERIC database.

Gass, M. A. (1986). The effects of a wilderness orientation program on incoming students to a university setting. (Unpublished Dissertation, University of Colorado, Boulder.)

Gass, M. A. (1990). The longitudinal effects of an adventure orientation program on the retention of students. Journal of College Student Development, 31, 33-38.

Gass, M.A., Garvey, D. E. \& Sugerman, D. A. (2003). The long term effects of a first-year student wilderness orientation program. Journal of Experiential Education, 26, 34-40.

Giddan, N. S. (1988). Community and social support for college students. Springfield, IL: Thomas.

Glass, J., \& Benshoff, J. (2002). Facilitating group cohesion among adolescents through challenge course experiences. Journal of Experiential Education, 25(2), 268-277.

Gillis, H. L. (1981). The Effects of a Camping/Construction Experience on the Self Concepts, Locus of Control, and Academic Achievement of High School Students. (Master's thesis, Middle Tennessee State University). Retrieved from ERIC database.

Gillis, H. L., \&Speelman, E. (2008). Are Challenge (Ropes) Courses an Effective Tool? A MetaAnalysis. Journal of Experiential Education, 31(2), 111-135. Retrieved from ERIC database. 
Goldenber, M. A., Klenosky, D. B., O'Leary, J. T., \& Templin, T. J. (2000). A means-end investigation of ropes course experiences. Journal of Leisure Research, 32(2), 208-225. In A. Attrarian, \& G. T. Holden III (Eds.), The Literature and Research on Challenge Courses: An Annotated Bibliography (12-13). Raleigh, NC: North Carolina University.

Gordon, V. (1989). Origins and purposes of the freshman seminar. In M. L. Upcraft, \& H. N. Gardner(Eds.), The Freshman Year Experience: Helping Students Survive and Succeed in College (183-197). San Francisco, CA: Jossey-Bass Inc.

Hackett, G., \& Betz, N. E. (19981). A self-efficacy approach to the career development of women. Journal of Vocational Behavior, 24(2), 326-339.

Hans, T. A. (2000). A meta-analysis of the effects of adventure programming on locus of control. Journal of Contemporary Psychotherapy, 30, 33-60.

Harlan, N. J., \& Grout, S. J. (2008). Freshmen Orientation Programs and Curriculum Integration into Challenge Course Activities [Power Point Slides]. Retrieved from West Virginia University.

Hatch, K. D., \& McCarthy, C. J. (2005). Exploration of Challenge Courses' Long-Term Effects on Members of College Student Organizations. Journal of Experiential Education, 27(3), 245264. Retrieved from ERIC database.

Hattie, J., Marsh, H. W., Neil, J. T., \& Richards, G. E. (1997). Adventure education and Outward Bound: Out-of-class experiences that make a lasting difference. Review of Educational Research, 67, 43-87.

Healey, M., \& Jenkins, A. (2000). Kolb's Experiential Learning Theory and Its Application in Geography in Higher Education. Journal of Geography, 99(5), 185-195.

History of the First Year Seminar \& University 101 Program. (n.d.). Retrieved March 30, 2009, from http://www.sc.edu/univ101/aboutus/ history.html

Hoff, A., \& Ellis, G. (1992). Influence of agents of leisure socialization on leisure self-efficacy of university students. Journal of Leisure Research, 24(2), 114-126.

Hsieh, P., Sullivan, J. R. \& Guerra, N. S. (2007). A Closer Look at College Students: Self-Efficacy and Goal Orientation. Journal of Advanced Academics, 18(3) 454-476.

James, T. (1980). Can the mountains speak for themselves? Un-published manuscript, Outward Bound School, Denver, CO: Retrieved November 10, 2009, from http://wilderdom.com/facilitation/Mountains.html 
Jones, J. J., \& Hinton, J. L. (2007). Study of self-efficacy in a freshman wilderness experience program: Measuring general versus specific gains. Journal of Experiential Education, 29, 382-385. Retrieved from ERIC database.

Kolb, D. A. (1984). Experiential learning: Experience as the source of learning and development. New Jersey: Prentice-Hall.

Kolb, D. A., Boyatzis, R., \& Mainemelis, C. (2000). Experiential Learning Theory: Previous Research and New Directions. In R. J. Sternberg \& L. F. Zhang (Eds.), Perspectives on cognitive learning, and thinking styles. Lawrence, NJ: Erlbaum.

Litt, M. (1988). Self-efficacy and perceived control: Cognitive mediators of pain tolerance. Journal of Personality and Social Psychology, 54(1), 149-160.

MacRae, S., Moore, C., Savage, G., Soehner, D. \& Priest, S. (1993). Changes in risk taking propensity resulting from a rope course experience. Journal of Adventure Education and Outdoor Leadership, 10(2), 10-13. In A. Attrarian, \& G. T. Holden III(Eds.), The Literature and Research on Challenge Courses: An Annotated Bibliography (12-13). Raleigh, NC: North Carolina University.

Martin, B., Cashel, C., Wagstaff, M., \& Breunig, M. (2006). Outdoor leadership: Theory and practice. Champaign, IL: Human Kinetics.

McGowan, M. (1997). A More Conscientious Use of Metaphor in Adventure Education. The Bradford Paper Annuals

Morris, E. K. (1987), Utilizing a ropes course in staff orientation. In A. Attrarian, \& G. T. Holden III(Eds.), The Literature and Research on Challenge Courses: An Annotated Bibliography (12-13). Raleigh, NC: North Carolina University.

Neil, J. (2006). What is a ropes challenge course? Retrieved April 9, 2009, from www.wilderdom.com Web site: http://wilderdom.com/ropes/RopesWhatls.html

Neil, J. T., \& Richards, G. E. (1998). Does outdoor education really work? A summary of recent meta-analysis. Australian Journal of Outdoor Education, 3, 1-8.

Nyhus, R. A., Napper-Owen, G., \& Phillips, D. A. (1996). The effect on an adventure education experience on physical self-efficacy of college students. In A. Attrarian, \& G. T. Holden III(Eds.), The Literature and Research on Challenge Courses: An Annotated Bibliography (12-13). Raleigh, NC: North Carolina University.

Owen, S. V., \& Froman, R. D., (1988). Development of a College Academic Self-Efficacy Scale. New Orleans, LA: The Annual Meeting of the National Council on Measurement in Education. Retrieved from ERIC database. 
Perigo, D. J. \& Upcraft, M. L., (1989). Orientation programs. In M. L. Upcraft, \& H. N. Gardner(Eds.), The Freshman Year Experience: Helping Students Survive and Succeed in College (82-94). San Francisco, CA: Jossey-Bass Inc.

Porter, S. R., and R. L. Swing. 2006. Understanding how first-year seminars affect persistence. Research in Higher Education 47 (1): 89-109.

Powers, K. R. (1983). The effects of physical challenge training on self-concept and locus of control (Doctoral dissertation, University of Pittsburgh). Dissertation Abstracts International, 44, 2364A.

Priest, S., \& Lesperance, M. (1994). Time Series Trends in Corporate Team Development. Journal of Experiential Education, 17(1), 34-39. Retrieved from ERIC database.

Propst, D. B., \& Koesler, R. A. (1998). Bandura goes outdoors: Role of self-efficacy in the outdoor leadership development process. Leisure Sciences, 20, 319-344.

Robinson, D. A. G., Burns, C. F., \& Gaw, K. F. (1996). Orientation programs: A foundation for student learning and success. New Directions for Student Services, 75, 55-68.

Rohnke, K. (1999). Ropes Courses: A Constructed Adventure Environment. In J. Miles \& S. Priest (Eds). Adventure Programming (pp. 347-352). State College, Pennsylvania: Venture Publishing, Inc.

Rohnke, K., Rogers, D., Tait, C. M., \& Wall, J. B. (2007). The complete ropes course manual. Dubuque, IA: Kendall/Hunt.

Sanders, P. \& Sanders, L. (1998). Measuring confidence in academic study: A summary report [Electronic Version]. Journal of Research in Education and Psychopedagogy, 1, 1-17.

Schunk, D. (1984). Self-efficacy perspective on achievement behaviour. Educational Psychology, 19(1), 48-58.

Sibthorp, J. (2003). An empirical look at Walsh and Golbin's adventure education process model: Relationship between antecedent factors, perceptions of characteristics of an adventure education experience, and changes in self-efficacy. Journal of Leisure Research, 35, 80-106.

Solberg, V. S., O'Brien, K., Villareal, P., Kennel, R., \& Davis, B., (1993). Self-Efficacy and Hispanic College Students; Validation of the College Self-Efficacy Instrument. Hispanic Journal of Behavioral Sciences, 15 (80-95) Retrieved from http://hjb.sagepub.com/cgi/content/refs/15/1/80 
Stadler, K. \& Kotze, M. E., (2006). The influence of a ropes course development programme on the self-concept and self-efficacy of young career officers. SA Journal of Industrial Psychology, 32 (1), 25-32.

Steffen, J. \& Cross, R. (1994). Adventure education for at-risk college students. Reaseach Quarterly for Exercise \& Sport, 65(1), A-83. In A. Attrarian, \& G. T. Holden III(Eds.), The Literature and Research on Challenge Courses: An Annotated Bibliography (12-13). Raleigh, NC: North Carolina University.

Stogner, J. (1978). The effects of a wilderness experience on self-concept and academic performance (Doctoral dissertation, Virginia Polytechnic Institute and State University). Dissertation Abstracts International, 39, 4704A.

Sturdivant, V. A. (1991). The effect of ropes course elements on self-concept and affective behavior (Doctoral dissertation, University of North Texas, 1990). Dissertation Abstracts International, 52(02), 468A.

Stuhr, J. J. (1987). Classical American Philosophy; Essential Readings and Interpretive Essays. New York, NY: Oxford University Press, Inc.

Sung, Y. K. (2004). A determination of the effects of a ropes course on the self-esteem of undergraduate and graduate students (Doctoral dissertation, Florida International University, 2004). Dissertation Abstracts International, 65(11), 4073A.

Tinto, V. (1987). Leaving college: rethinking the causes and cures of student attrition. Chicago, IL: University of Chicago Press.

Wagstaff, M., (2003). History and Philosophy of Challenge Courses. In S. Wurdinger \& J. Steffen (Eds.), Developing Challenge Course Programs for Schools (3-16). Kendall Hunt.

Walsh, V., \& Golins, G. L. (1976). The exploration of the Outward Bound process. Denver, CO: Colorado Outward Bound School.

Witman, J. P. (1993). Characteristics of adventure programs valued by adolescents in treatment. Therapeutic Recreation Journal, 27(1), 44-50.

Witter, B. E. (2004). The impact of facilitation of challenge initiatives on college social selfefficacy generality (Doctoral dissertation, The University of Utah, 2004). Dissertation Abstracts International, 65(09), 3566A.

Wolf, F. M. (1986). Meta-analysis: Quantitative methods for research synthesis. Beverly Hills, CA: Sage. 
Wolfe, B. D. \& Samdahl, D. M. (2005). Challenging assumptions: examining fundamental beliefs that shape challenge course programming and research. Journal of Experiential Education, 28(1), 25-43. Retrieved from ERIC database.

Yoshino, A. (2004). Environmental outcomes of wilderness-based programs of different lengths. Journal of Experiential Education, 27, 314-317. Retrieved from ERIC database. 


\section{Appendices}

Appendix A Cover Letter to Odyssey Participants.................................................. 94

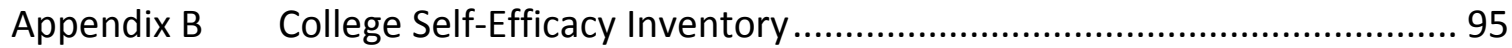

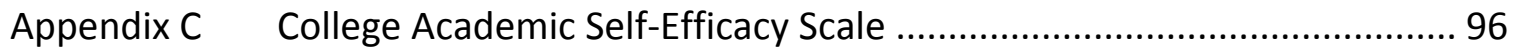

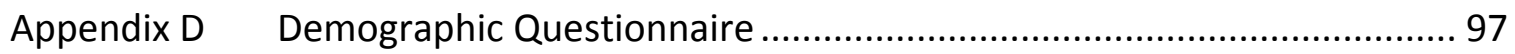




\section{Appendix A Cover Letter to Odyssey Participants}

Dear Adventure West Virginia Odyssey Participant:

Thank you for agreeing to participate in this study about education curriculum delivery. The questions in this packet relate to your current transition into college. This is an opportunity for you to help direct the design of future Adventure West Virginia Programs. Your responses are critical to the success of this outdoor orientation program and this project.

It should take you about 15 minutes to complete the question booklet. You do not have to answer every question. Your answers are strictly confidential and your name will in no way be connected with the results of the project. This study is being conducted by West Virginia University in meeting the requirements for a master's thesis. This is a research project.

When you have completed the question booklet please return it to the researcher you have received it from. We are grateful for the help you have given us. If you have any questions, please feel free to ask the research onsite or contact us at the following information:

Simon.grout@mail.wvu.edu

340-685-4610

Sincerely,

Simon Grout, B.S 
Directions: Think about youself as a college student. For each statements below, circle the number that best represents your confidence.

How confident are you that you could successfully complete the following tasks: (Circle one number).

$\begin{array}{ll}\text { 0-totally unconfident } & \text { 5-somewhat confident } \\ \text { 1-very unconfident } & \text { 6-confident } \\ \text { 2-unconfident } & \text { 7-very confident } \\ \text { 3-somewhat unconfident } & \text { 8-totally confident } \\ \text { 4-undecided } & \end{array}$

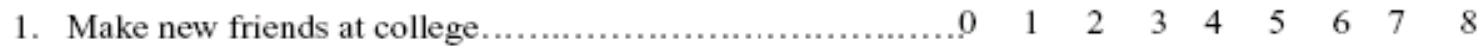

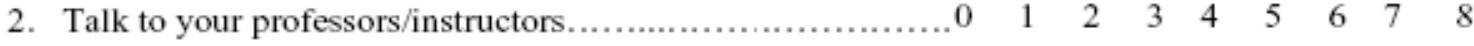

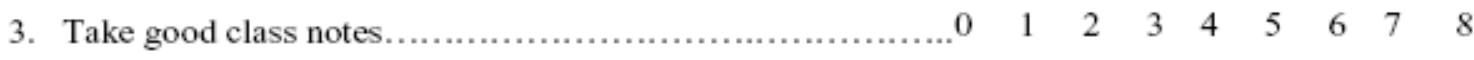

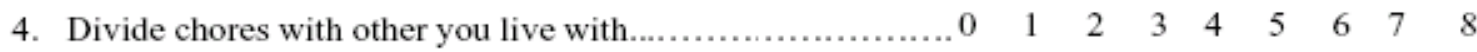

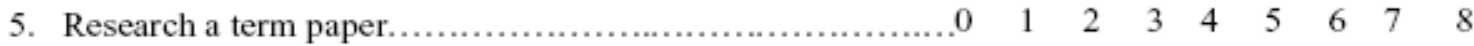

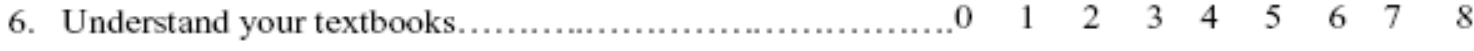

7. Get a date when you want one........................................ $9 \begin{array}{lllllllll} & 1 & 2 & 3 & 4 & 5 & 6 & 7 & 8\end{array}$

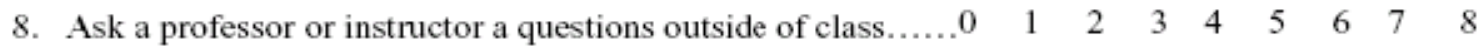

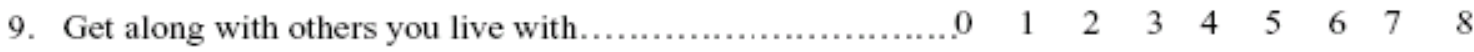

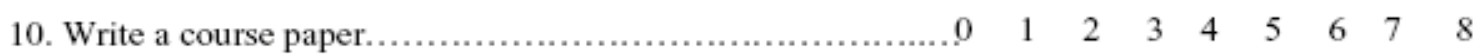

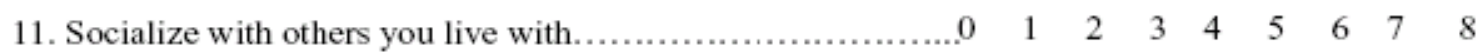

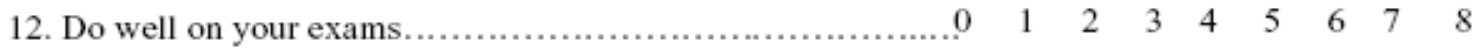

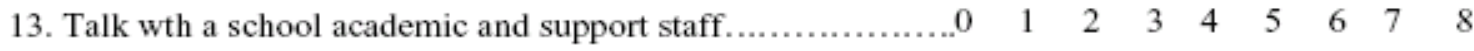

14. Manage your time effectively................................ $9 \begin{array}{lllllllll} & 1 & 2 & 3 & 4 & 5 & 6 & 7 & 8\end{array}$

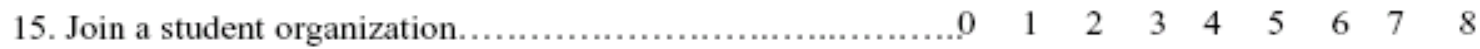

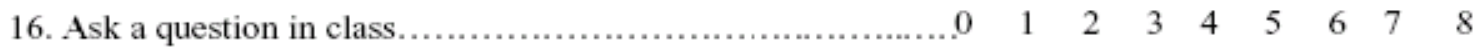

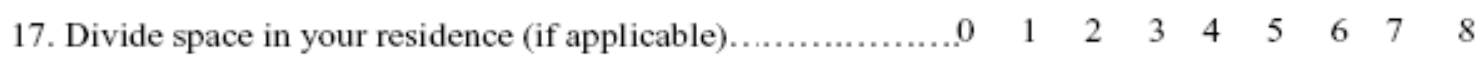

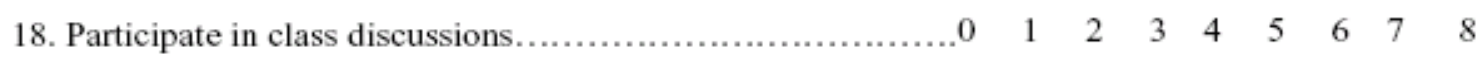

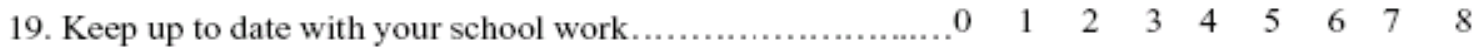




\section{Appendix C College Academic Self-Efficacy Scale}

\section{Directions:_How much confidence do you have about doing each of the behaviors listed below?}

For each statement below, circle the letter that best represents your confidence.
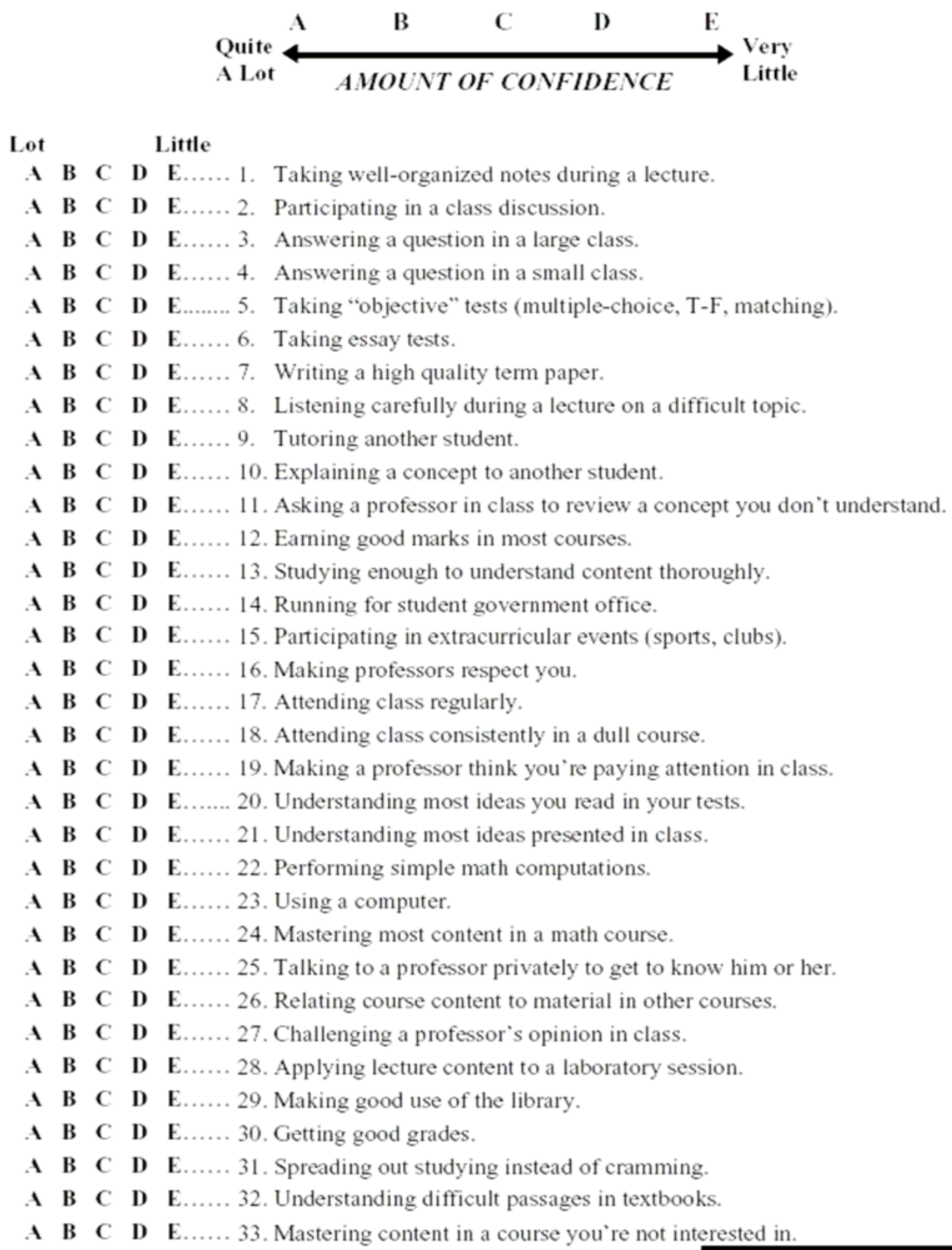


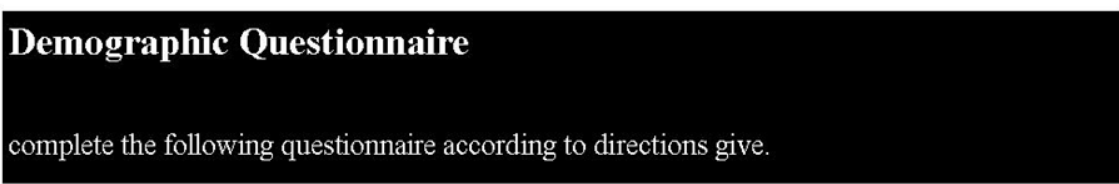

Circle one
A. Gender:
Male
Female

Circle all that apply

B. What race(s) do you identify yourself with:
African American,
Caucasian,
Asian,
Hispanic,
Native American,
Other: Pleas Specify

Fill in the Blank
C. Age:
D. Home State:

John $\mathrm{H}$.

Thank you for taking the

time to complete this survey!

Please return this question booklet

to the researcher. 